\title{
Study on variable pitch strategy in H-type wind turbine considering effect of small angle of attack
}

Zhao, Zhenzhou; Qian, Siyuan; Shen, Wenzhong; Wang, Tongguang; Xu, Bofeng; Zheng, Yuan; Wang, Ruixin

Published in:

Journal of Renewable and Sustainable Energy

Link to article, DOI:

$10.1063 / 1.4989795$

Publication date:

2017

Document Version

Publisher's PDF, also known as Version of record

Link back to DTU Orbit

Citation (APA):

Zhao, Z., Qian, S., Shen, W., Wang, T., Xu, B., Zheng, Y., \& Wang, R. (2017). Study on variable pitch strategy in $\mathrm{H}$-type wind turbine considering effect of small angle of attack. Journal of Renewable and Sustainable Energy, 9(5), [053302]. https://doi.org/10.1063/1.4989795

\section{General rights}

Copyright and moral rights for the publications made accessible in the public portal are retained by the authors and/or other copyright owners and it is a condition of accessing publications that users recognise and abide by the legal requirements associated with these rights.

- Users may download and print one copy of any publication from the public portal for the purpose of private study or research.

- You may not further distribute the material or use it for any profit-making activity or commercial gain

- You may freely distribute the URL identifying the publication in the public portal 


\section{Study on variable pitch strategy in H-type wind turbine considering effect of small angle of attack}

Zhenzhou Zhao, Siyuan Qian, Wenzhong Shen, Tongguang Wang, Bofeng Xu, Yuan Zheng, and Ruixin Wang

Citation: Journal of Renewable and Sustainable Energy 9, 053302 (2017); doi: 10.1063/1.4989795

View online: http://dx.doi.org/10.1063/1.4989795

View Table of Contents: http://aip.scitation.org/toc/rse/9/5

Published by the American Institute of Physics

\section{Articles you may be interested in}

In search of the wind energy potential

Journal of Renewable and Sustainable Energy 9, 052301 (2017); 10.1063/1.4999514

Modeling of wind turbine vortex generators in considering the inter-effects between arrays

Journal of Renewable and Sustainable Energy 9, 053301 (2017); 10.1063/1.4997039

Measurements of heat and humidity fluxes in the wake of offshore wind turbines

Journal of Renewable and Sustainable Energy 9, 053304 (2017); 10.1063/1.5003811

Regulating power management in interconnected microgrids

Journal of Renewable and Sustainable Energy 9, 055502 (2017); 10.1063/1.5003003

Study and comparison between two DTC strategies of induction machine fed by direct matrix converter Journal of Renewable and Sustainable Energy 9, 055501 (2017); 10.1063/1.5002769

Unsteady Navier-Stokes studies on loads, wake, and dynamic stall characteristics of a two-bladed vertical axis wind turbine

Journal of Renewable and Sustainable Energy 9, 053303 (2017); 10.1063/1.5003772 


\title{
Study on variable pitch strategy in H-type wind turbine considering effect of small angle of attack
}

\author{
Zhenzhou Zhao, ${ }^{1,2, a)}$ Siyuan Qian, ${ }^{1}$ Wenzhong Shen, ${ }^{2}$ Tongguang Wang, ${ }^{3}$ \\ Bofeng Xu, ${ }^{1}$ Yuan Zheng, ${ }^{1}$ and Ruixin Wang ${ }^{1}$ \\ ${ }^{1}$ Energy Technology Engineering Research Center of Ministry of Education of Renewable, \\ Hohai University, Nanjing, Jiangsu Province 210098, China \\ ${ }^{2}$ Department of Wind Energy, Technical University of Denmark, Lyngby 2800, Denmark \\ ${ }^{3}$ Jiangsu Key Laboratory of Hi-Tech Research for Wind Turbine Design, Nanjing University \\ of Aeronautics and Astronautics. Nanjing, Jiangsu Province 210016, China
}

(Received 12 June 2017; accepted 21 August 2017; published online 19 September 2017)

\begin{abstract}
Variable-pitch (VP) technology is an effective approach to upgrade the aerodynamics of the blade of an H-type vertical-axis wind turbine (VAWT). At present, most of the research efforts are focused on the performance improvement of the azimuth angle owing to the large angle of attack (AoA). On the blade circular path of an H-type VAWT, there are two azimuth positions where torques are negative, and the performance is the poorest. The vicinity zones of the two azimuths also have low performance and greatly weaken the overall productivity of VAWT. In this paper, we propose a new technology that, unlike the traditional VP-technology, focuses mainly on the aerodynamics improvement of the azimuth position with small AoA. The purpose of this novel approach is to widen the band of azimuth positions with high performance and eventually enhance the power efficiency of the overall VAWT. The performance of the new VP-VAWT is predicted using the Double Multiple Streamtubes model and Prandtl's mathematics to evaluate the blade tip loss. Compared with the fixed-pitch (FP) blade, the VP-blade has a wider zone of the max AoA and tangential force in the upwind half-circle and yields the two new larger max values in the downwind half-circle. The new VP-strategy considerably narrows the two low-torque zones near the $0^{\circ}$ and $180^{\circ}$ azimuths and markedly widens the high-torque azimuth zone; the torque distribution appears in a trapezoidal shape in the upwind region and an M-like shape in the downwind region. The power distribution in the swept area of turbine changes from an arched shape of the FP-VAWT into a rectangular shape of the VP-VAWT. At last, an $18.9 \%$ growth in power efficiency is achieved. All of the above results confirm that the new VP-technology can effectively improve VAWT performance and also widens the highest performance tip speed ratio zone which makes the turbines capable of running with high efficiency in wider zones. Published by AIP Publishing.

[http://dx.doi.org/10.1063/1.4989795]
\end{abstract}

\section{INTRODUCTION}

Today, most wind energy comes from large, three-bladed horizontal-axis wind turbines (HAWTs). Darrieus wind turbines are lift-type vertical-axis wind turbines (VAWTs), in which the lift acts on the blades, causing spinning of the rotor and hence resulting in the generation of electricity. Darrieus VAWTs, whose design was first patented in 1931 and then named after their French inventor G. M. Darrieus (Schonborn and Chantzidakis, 2007), are the most efficient among all other types of VAWTs. Generally, Darrieus VAWTs can attain coefficients of power which are comparable to those of HAWTs but have several potentially significant advantages

a) Author to whom correspondence should be addressed: joephy@163.com 
over HAWTs (Cooper and Kennedy, 2004). For example, VAWTs accept wind coming from any directions and can operate in harsher wind conditions, including lower wind-speeds and more turbulence (Mertens, 2006). VAWTs are sometimes installed on building roofs as a way of capturing energy in windy urban areas, providing distributed power generation (Sagharichi et al., 2016). The application of VAWTs in wind power generation grows slowly as compared with that of HAWTs, the essential reason of which is that the conventional fixed-pitch (FP)VAWTs have some inherent shortcomings such as problems of lower starting torque and relatively low power efficiency than those of HAWTs (Firdaus et al., 2015) and the narrow band of the tip speed ratio (TSR) with high performance (Liu et al., 2015).

Darrieus VAWTs can be divided into several categories according to their configurations: egg beater-shaped turbines with curved blades (also called $\Phi$-type turbines), Giromill turbines with straight blades, variable-geometry oval-trajectory Darrieus turbines, etc. (Cooper and Kennedy, 2004). Giromill turbines can have any number of blades starting from two and reaching the five-bladed configurations of the commercially available turbines. However, the most common configurations are with two- and three-bladed designs (Bhutta et al., 2012). Among these, the two-bladed design of the Giromill turbine is frequently referred to as the H-type turbine. In addition, due to the similar fundamental theoretical basis of extracting kinetic energy from moving fluid and converting it into useful electrical power, H-type turbines are also employed as marine current turbines which encounter the same problems as VAWTs, such as low efficiency and poor self-starting (Schonborn and Chantzidakis, 2007 and Hantoro et al., 2011). Therefore, extensive researches have been conducted on H-type turbines of both wind and tidal energies to investigate their running mechanism, and a large number of approaches have been attempted to improve the efficiency of the turbines, including aerofoil upgradation (Mohamed et al., 2015; Claessens, 2006; and Sengupta et al., 2016), structure optimization (Kirke, 1998 and Eboibi et al., 2016), and utilization of Variable-pitch (VP)-technology (Shires and Kourkoulis, 2013).

The blade is definitely one of the most important components of wind turbines and plays a key role in the production of electrical power (Xisto et al., 2014). The blades of H-type VAWTs can be designed as FP- or VP-configurations. Apart from having the potential to overcome the self-starting issues associated with VAWTs, the VP-design commonly achieves a comparatively higher power coefficient (Paraschivoiu et al., 2009) and is thus one of the effective approaches to accomplish performance improvement. Large-scale investigations on the aerodynamics and optimization of their pitch angle have been performed by using 2D or 3D computational fluid dynamics (CFD) modeling (Sagharichi et al., 2016 and Elkhoury et al., 2015), Double Multiple Streamtubes (DMST) model (Liu et al., 2015), and other experiments (Elkhoury et al., 2015 and Hantoro et al., 2011). VP-technologies can be categorized into two basic types: active and passive. Among the active VP-technologies, two main strategies of pitch control with two different movement curves are commonly used; the first one is the cyclic VPtechnology, in which the changes of the pitch angle versus azimuth angle are of sinusoidal curve. Schonborn and Chantzidakis, 2007 studied the mechanism of a cyclic VP-marine current turbine, and the results showed that the turbine obtained a reliable self-starting ability and the efficiency was improved by up to $20 \%$. Erickson et al. (2011) tested a VP-VAWT controlled by a cyclic VP-strategy in a wind tunnel over a wide range of design and operational variables and achieved a 35\% efficiency improvement over FP-VAWT. Chougule and Nielsen (2014) designed a 500-W VAWT to implement the pitch control mechanism using the cyclic VPtechnology. Its aerodynamics was predicted using the DMST model, and the results showed that only $5^{\circ}$ of the pitch angle amplitude increased the power coefficient of the VAWT by $12 \%$. Another approach is the cycloidal VP-technology, in which the changes of the pitch angle are much closer to a sinusoidal curve. Zhang et al. (2013) investigated the aerodynamics of VP-VAWT controlled by a cycloidal strategy. Compared with the FP-VAWT, the aerodynamic performance in the upwind half-circle of VAWT with the optimized blade pitch angle was greatly improved, particularly in the azimuth region from $90^{\circ}$ to $180^{\circ}$; the effective region was expanded and was nearly twice larger than that of the FP case. Hwang et al. (2009) conducted studies on the productivity of a cycloidal water turbine by CFD and experiments. The optimal parameters were determined, and the performance of the turbine was approximately $70 \%$ better 
than that of the FP-turbine. Furthermore, a substantial amount of research work on cycloidal VP-marine current turbines was conducted to overcome their drawbacks and improve the overall performance of the turbines in China (Wang et al., 2004 and Zhang et al., 2011).

However, both VP-strategies mentioned above emphasize mainly the performance enhancement of azimuths with a high angle of attack (AoA) in the case of FP. The effects on the blade revealed by the above studies can be summarized as follows: both $90^{\circ}$ and $270^{\circ}$ azimuths have the biggest AoA in FP-VAWTs, and the largest growth of performance will be obtained in the same positions of VP-VAWTs. While, when the biggest AoA is approximate to the critical value, the magnitude of the largest growth is much small, other azimuths would have smaller changes of performance. This phenomenon can be directly seen in Fig. 1 (Kosaku et al., 2002). To solve this problem, we proposed a new VP strategy intended to mainly upgrade the performance of azimuths with smaller AoA in FP-VAWTs and consequently widen the highperformance azimuth zone or narrow the zones of poor performance. The work described in this paper was conducted by using the DMST model.

\section{EXPLANATION OF THE DARRIEUS CONCEPT}

\section{A. Basic theory of the Darrieus turbine}

The Darrieus turbine is a cross-flow machine whose axis of rotation meets the flow of the working fluid at right angles. Considering the 2D case of a blade moving in a circular path (illustrated in Fig. 2), the rotating blade experiences a changing resultant flow, which is the vector sum of the local wind speed and the blade's own speed. Both the AoA and the magnitude of resultant velocity vary with the azimuth position of the blade. In mathematical models, the path circle is usually divided into two half-circles by the line connecting the two azimuths $\left(0^{\circ}\right.$ and $180^{\circ}$ ): an upwind half-circle and a downwind half-circle. In general, the resultant flow always comes from the upwind side of the blade: the outer side on the upwind half-circle and the inner side on the downwind half-circle (Islam et al., 2008). At small non-zero AoAs, provided that the drag is small or the lift is large enough, the blade overcomes the drag and contributes to the positive torque to the turbine on which it is mounted. This torque is used to drive load and extract energy from the wind. Due to the oscillating AoA, in contrast to the case of HAWT, the blade of the VAWT always produces fluctuating torque (Fig. 3) even in steady conditions (Zhao et al., 2017).

The blades employ typically symmetrical airfoil sections fixed tangentially to the circular path on which they rotate. Throughout one rotation of the turbine, every blade passes through a whole range of AoA of both positive and negative values. At $0^{\circ}$ and $180^{\circ}$ azimuths, the relative

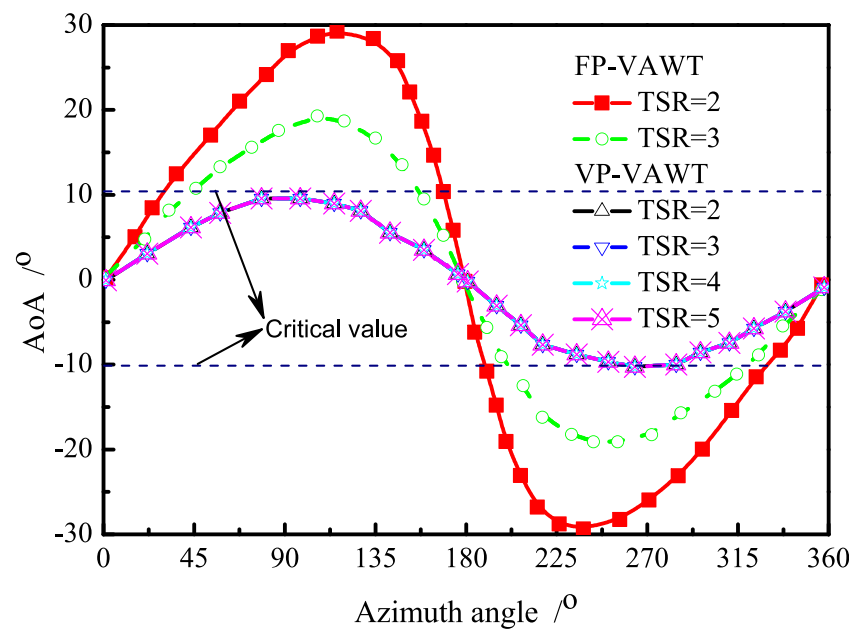

FIG. 1. Changes of AoA in traditional VP-VAWT (Kosaku et al., 2002). 


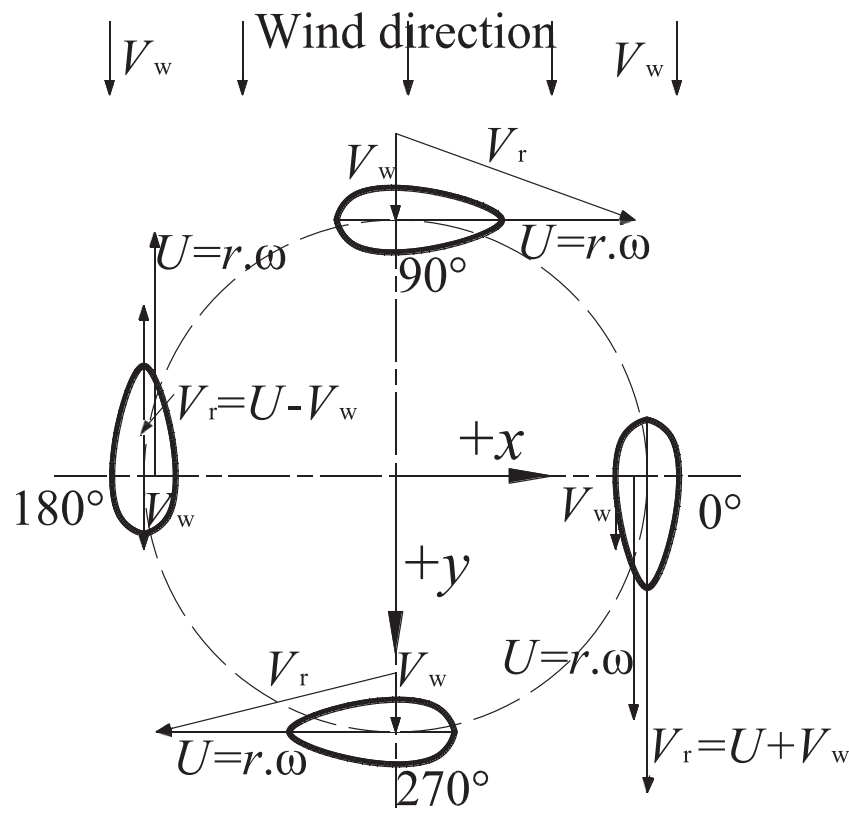

FIG. 2. Illustration of the Darrieus rotor.

movement of the blade and working fluid are directly opposite (Fig. 2), which contributes to two zero AoAs according to the velocity triangle. Zero AoA results in zero lift, thereby causing the two biggest negative torques characterized as brake torques at $0^{\circ}$ and $180^{\circ}$ azimuths. Due to $V_{\mathrm{r}}=U+V_{\mathrm{w}}$ at $0^{\circ}$ and $V_{\mathrm{r}}=U-V_{\mathrm{w}}$ at $180^{\circ}$ (here, $V_{\mathrm{r}}$ is the magnitude of the resultant flow, $U$ is the magnitude of the tangential flow, and $V_{\mathrm{w}}$ is the magnitude of the upwind flow), the $0^{\circ}$ position has a larger brake torque (Fig. 3). The vicinities of the two azimuths also have negative values because the lift is not sufficient to overcome the drag caused by the high resultant speed. The other two azimuths $\left(90^{\circ}\right.$ and $\left.270^{\circ}\right)$, where the directions of the upwind flow and tangential flow are vertical to each other (Fig. 2), exhibit the maximum AoAs and torques (Fig. 3). The former azimuth has better aerodynamics than the latter due to the higher upwind speed in the former position.

\section{B. Cyclical VP-strategy}

VP-VAWTs have been investigated since the 1970s and invariably found to provide greater efficiency than FP-VAWTs. Because a VAWT blade is subject to cyclic variations in the wind

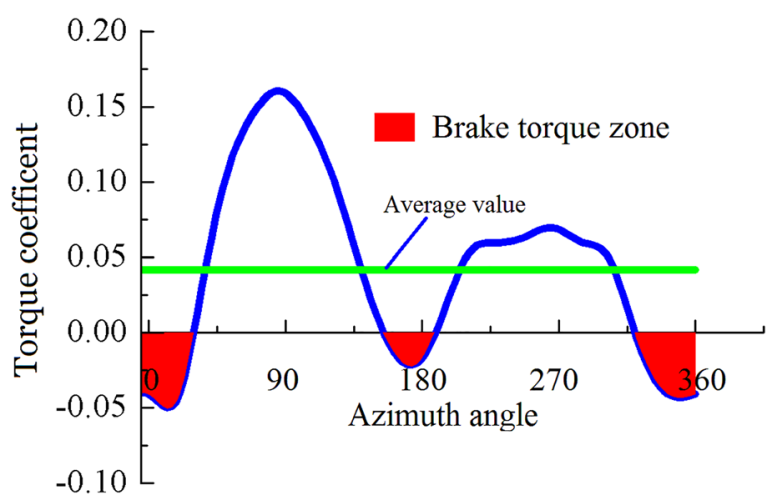

FIG. 3. Curve of the torque coefficient of a single blade. 
speed and AoA (Fig. 2), efficiency improvements can result from the corresponding variations of the pitch angle of the blade to optimize the AoA at each point in its cycle (Erickson et al., 2011). Due to the cyclical fluctuations of the AoA of the blade, any improvements made to the AoA have to be of cyclic nature (Schonborn and Chantzidakis, 2007). The curve of the pitch angle is expressed by Eqs. (1) and (2),

$$
\begin{gathered}
\gamma=A_{\mathrm{c}} \sin (\theta), \\
A_{\mathrm{c}}=A_{\mathrm{s}}-\left(A_{\mathrm{s}} \frac{\lambda}{X_{0}}\right) \sin (\theta),
\end{gathered}
$$

where $\gamma$ is the variable value of the pitch angle changed with the azimuth, $A_{\mathrm{c}}$ is the max pitch angle at a certain TSR, $A_{\mathrm{s}}$ is the max pitch angle at all TSRs, $\lambda$ is the TSR, and $X_{0}$ is the TSR of $\max C_{\mathrm{P}}$ at zero $A_{\mathrm{c}}$.

As can be seen in Fig. 4, showing the changes in the pitch angle of the blade throughout one rotation, the change tendency in the pitch angle is almost the same as those in the AoA of the FP-VAWT. Due to the max AoA in the FP-VAWT, the two positions of $90^{\circ}$ and $270^{\circ}$ display the max pitch angle in the VP case. As a result, the pitch angle changes following a sinusoidal curve (Fig. 5).

\section{Cycloidal VP-strategy}

In cycloidal VP-VAWT, the blades have an oscillatory motion around their own axis, superimposed on the uniform rotation motion. This oscillatory motion is characterized by the following properties (Fig. 6). Considering a cross-section of the turbine, the lines normal to the profile chord for every blade position intersect a given point "P" during a complete revolution. From the triangle of velocity in Fig. 6, it can be seen that the two azimuths of $90^{\circ}$ and $270^{\circ}$ are still close to the maximum pitch angle in VP-VAWT, and $0^{\circ}\left(180^{\circ}\right)$ maintains the zero value. The overall pitch angle curve is expressed as Eq. (3) and depicted in Fig. 7. Two trends are obvious in both Eq. (3) and Fig. 6: (1) the closer proximity to $90^{\circ}\left(270^{\circ}\right)$ of the azimuth results in a

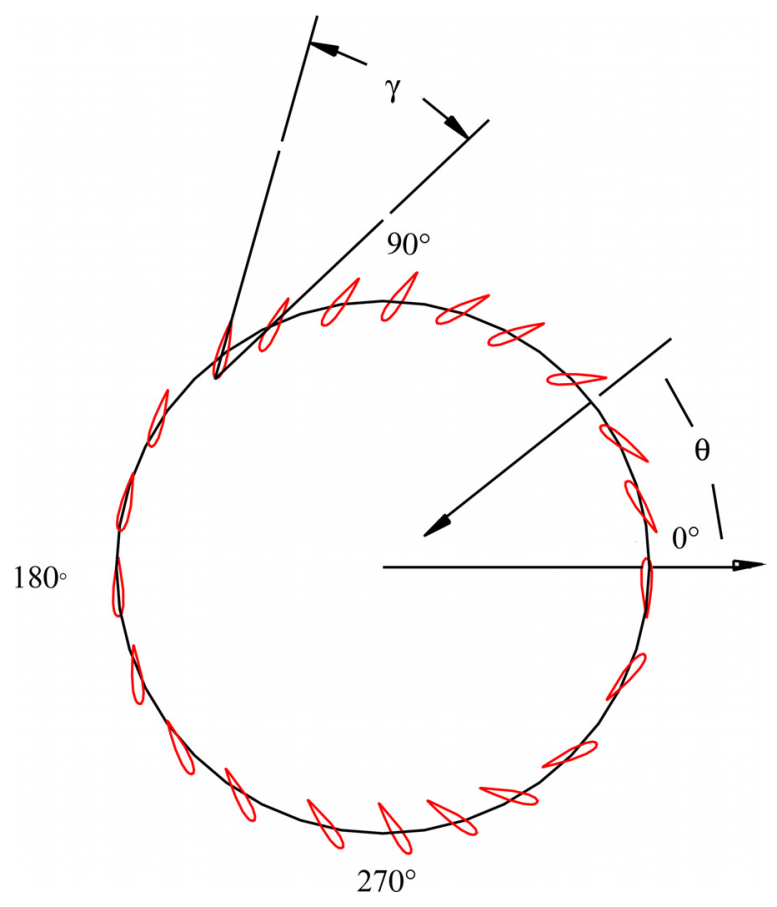

FIG. 4. Illustration of the cyclical variable pitch. 


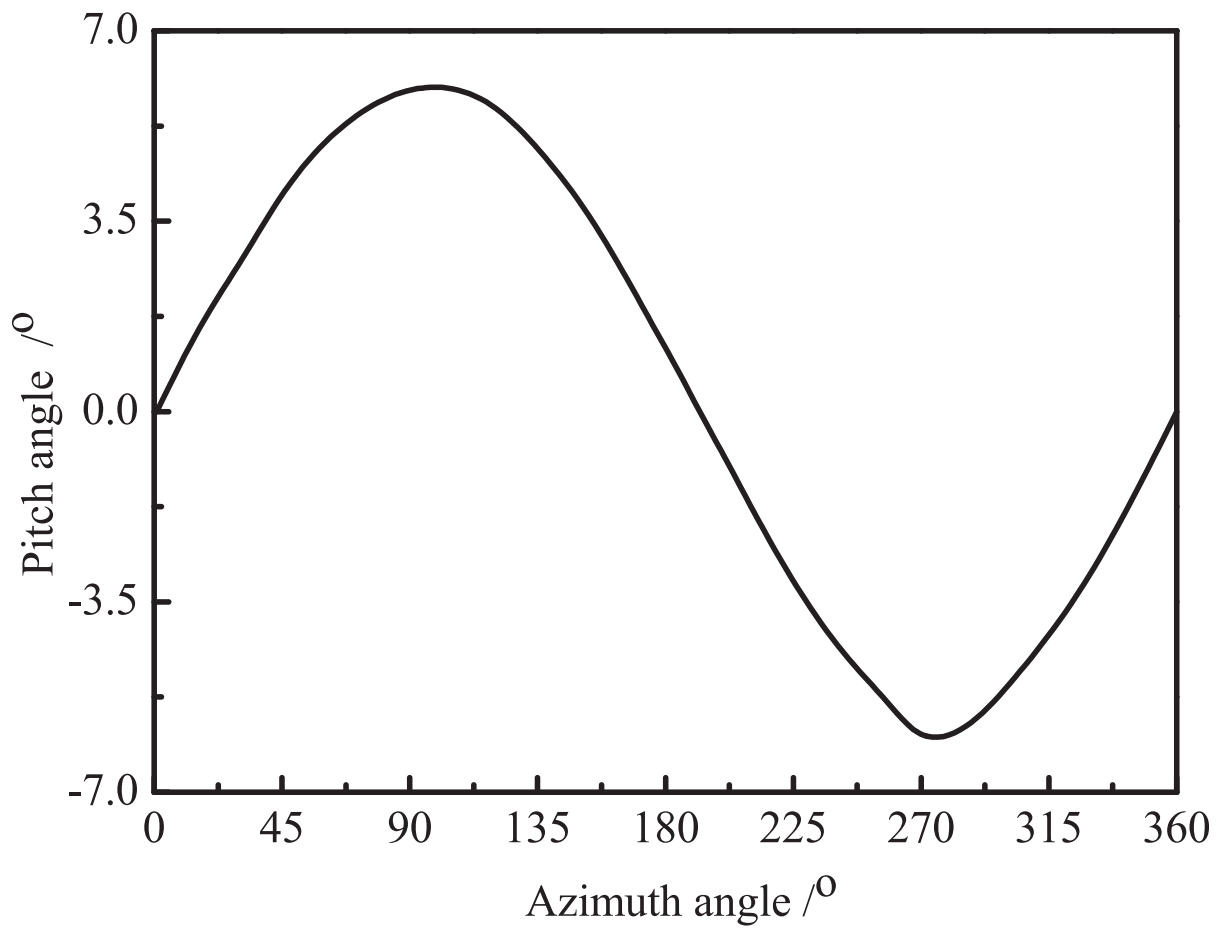

FIG. 5. Curve of the pitch angle in the cyclical strategy.

larger pitch angle; and (2) the variation speed of the pitch angle within the azimuth range of $90^{\circ}-270^{\circ}$ is much greater than that within the azimuth ranges of $0^{\circ}-90^{\circ}$ and $270^{\circ}-360^{\circ}$,

$$
\gamma=A_{\mathrm{c}} \sin \theta-\arctan \left(\frac{\sin \theta}{\cos \theta+\lambda}\right) .
$$

Equation (3) shows that the decrease in TSR leads to an increase in the pitch angle. At a certain TSR, the pitch angle will reach a negative value. This means that the AoA has surpassed the critical value, and the stall will happen at small TSR; thus, the pitch angle must be

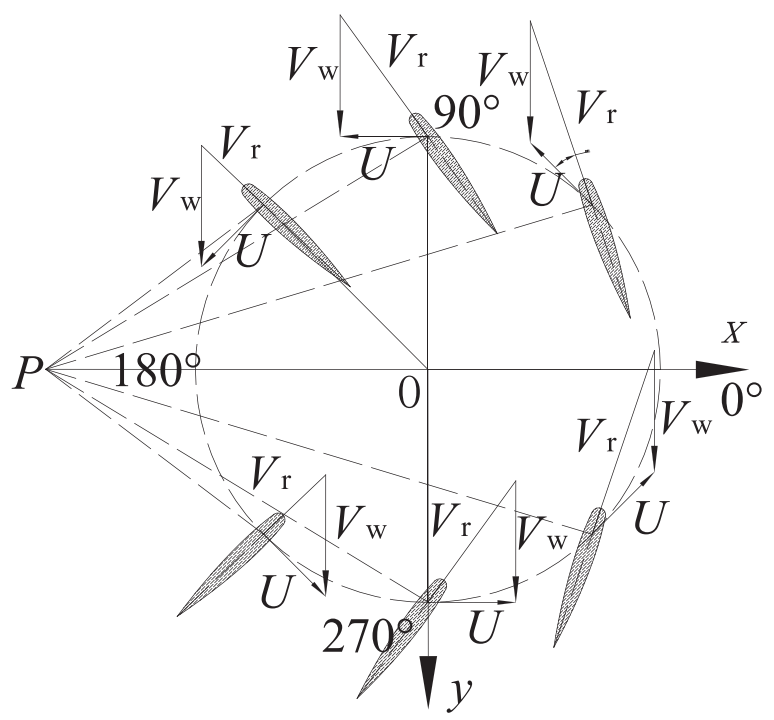

FIG. 6. Illustration of the cycloidal variable pitch (Camporealea and Magi, 2000). 


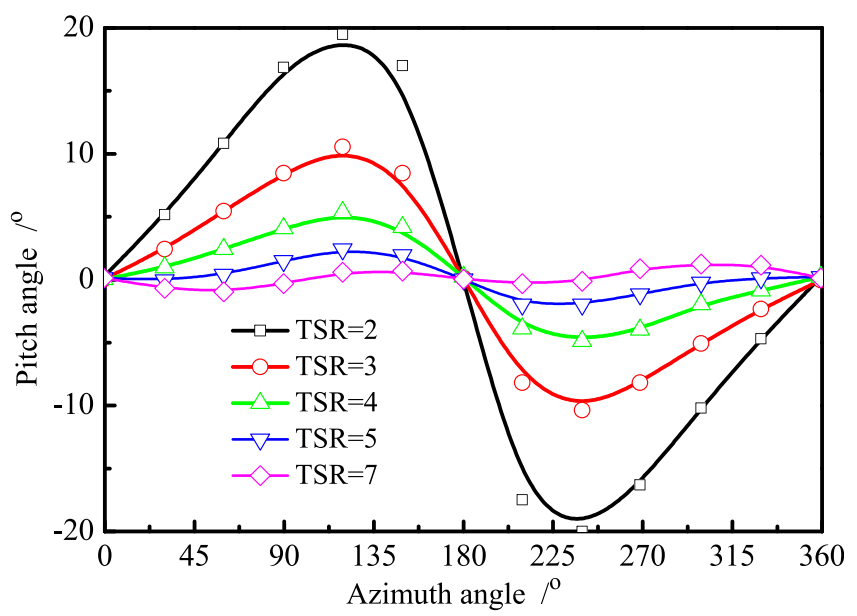

FIG. 7. Curves of the pitch angle.

adjusted in another direction of decreasing AoA to avoid the stall occurring on the upper surface of the blade.

\section{New VP-strategy}

Two traditional VP-strategies have one common point that the azimuth with a larger AoA will be offered a larger pitch angle. Affected by the performance, as expressed by the lift coefficient $\left(C_{\mathrm{L}}-\alpha\right)$ of airfoil, the blade has an optimum AoA (about $10^{\circ}$ ) corresponding to the highest performance. At values of AoA which are greater than the optimum value, the torque of the blade will decrease. Therefore, the space for performance enhancement in traditional VPstrategies, in which the max growth of AoA was designed to generate at azimuths of $90^{\circ}$ and $270^{\circ}$ with the larger AoA in the FP-blade, is exceedingly limited.

The new VP-strategy proposed in this paper focuses mainly on the performance improvement of azimuth owing to a small AoA in the FP-blade. The aim of the VP-strategy is to narrow the azimuthal range of poor performance and widen the range of high performance. As mentioned in Sec. II A, the positions of $0^{\circ}$ and $180^{\circ}$ are the transform points between the positive and negative AoAs, and thus, the effect of the pitch angle curve cannot avoid the zero AoAs. To accomplish our purpose, we divided the circular path into five zones (Fig. 8), and in different zones, the pitch angle had different variation tendencies. The pitch angle increased in the zones 1 and 5; it initially decreased but then rose again in zone 2 . In zone 3 , the pitch angle declined, whereas in zone 4 , it increased at first but then decreased. The four transform points among these zones were $0^{\circ}, 90^{\circ}, 180^{\circ}$, and $270^{\circ}$, and their pitch angles did not change (Fig. 9). In the whole, the curve of the new VP-strategy was constructed by two trigonometric function ones: a sinusoidal curve in the range of $112.5^{\circ}-202.5^{\circ}$ and a negative sinusoidal curve in the ranges of $202.5^{\circ}-360^{\circ}$ and $0^{\circ}-112.5^{\circ}$. As illustrated in Fig. 8, we defined the presence of a positive pitch angle when the blade rotated counterclockwise around its own axis, and the leading edge of the blade pointed toward the inner side of the circular path. In contrast, the angle was negative when the blade rotated and the leading edge pointed in the opposite direction. Overall differences between the four turbines are summarized in Table I.

\section{COMPUTATIONAL MODEL}

\section{A. Double multiple streamtubes model}

Momentum models were commonly used to calculate the streamwise aerodynamic force on the blades exerted by the flow through VP-VAWTs. Templin (1974) first applied the momentum theory to model VAWTs, using a Single Streamtube (SST) encompassing the entire turbine within which the momentum balance was calculated. The flow velocity within the streamtube 


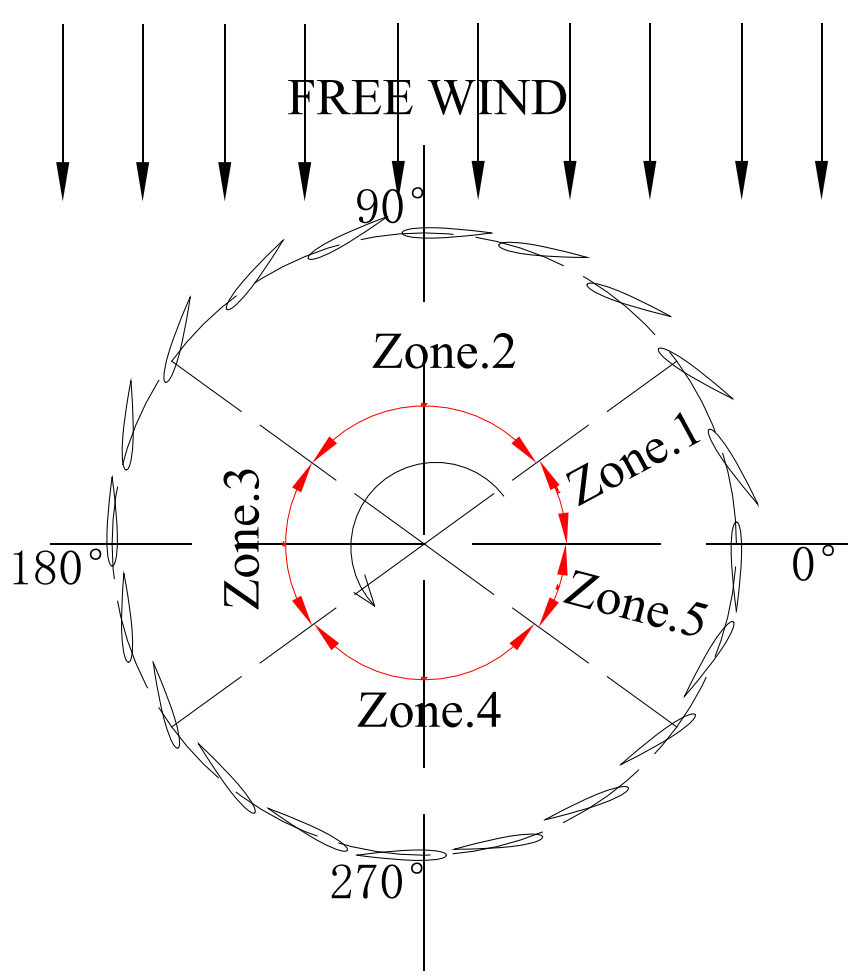

FIG. 8. Illustration of the new variable pitch.

was assumed to be uniform in the SST model, and the accuracy of modeling results needed to be promoted. Strickland (1975) extended the model in which the flow through the turbine was divided into several independent streamtubes. The momentum model was implemented separately for each streamtube, allowing an arbitrary variation in the inflow. Paraschivoiu and Delclaux (1983) divided the circular path into two half-circles: an upwind half-circle and a downwind half-circle; each streamtube was also divided into two halves, allowing for a difference between the upwind and downwind passes of each blade. This model is the so-called "Double Multiple Streamtubes (DMST)" model (Pawsey, 2002) in which the momentum balance is maintained separately for each half streamtube. The DMST model considers a partition

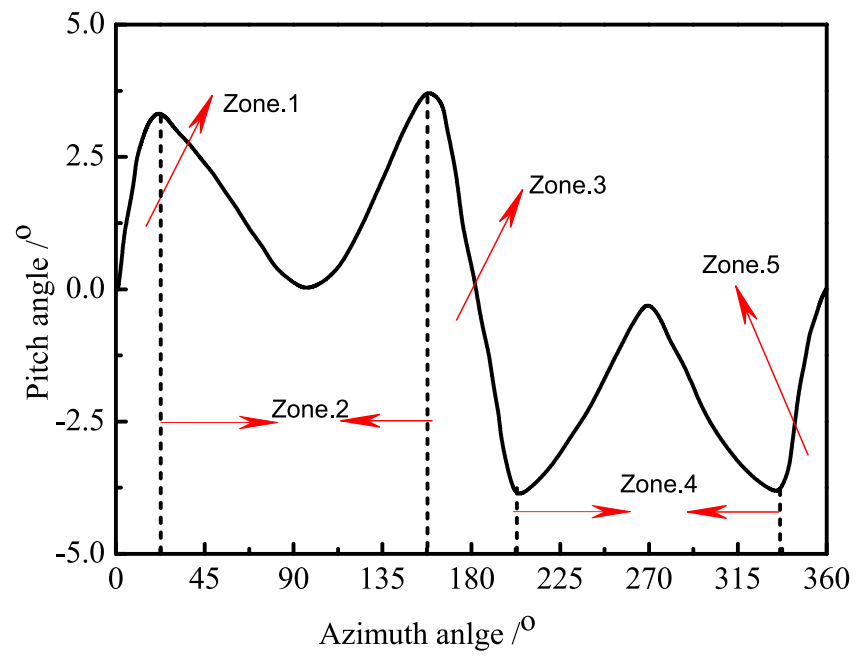

FIG. 9. Curve of the pitch angle in the new strategy. 
TABLE I. Comparison between four VAWTs.

\begin{tabular}{|c|c|c|c|c|c|}
\hline \multicolumn{2}{|c|}{ Items } & FP-VAWT & $\begin{array}{l}\text { VP-VAWT } \\
\text { (cyclical) }\end{array}$ & $\begin{array}{l}\text { VP-VAWT } \\
\text { (cycloidal) }\end{array}$ & $\begin{array}{l}\text { VP-VAWT } \\
\text { (author) }\end{array}$ \\
\hline \multicolumn{2}{|l|}{ Aerofoil } & $\begin{array}{c}\text { Symmetrical } \\
\text { aerofoil }\end{array}$ & $\begin{array}{l}\text { Symmetrical } \\
\text { aerofoil }\end{array}$ & $\begin{array}{l}\text { Symmetrical } \\
\text { aerofoil }\end{array}$ & $\begin{array}{l}\text { Symmetrical } \\
\text { aerofoil }\end{array}$ \\
\hline \multirow[t]{2}{*}{ AoA } & $\begin{array}{l}0^{\circ}\left(180^{\circ}\right) \\
\text { azimuth }\end{array}$ & 0 & 0 & 0 & 0 \\
\hline & $\begin{array}{c}90^{\circ}\left(270^{\circ}\right) \\
\text { azimuth }\end{array}$ & $\operatorname{Max}$ & Max & Close to max & Max(maybe) \\
\hline \multirow[t]{2}{*}{ Pitch angle } & $\begin{array}{l}0^{\circ}\left(180^{\circ}\right) \\
\text { azimuth }\end{array}$ & 0 & 0 & 0 & 0 \\
\hline & $\begin{array}{c}90^{\circ}\left(270^{\circ}\right) \\
\text { azimuth }\end{array}$ & 0 & $\operatorname{Max}$ & Close to max & 0 \\
\hline \multicolumn{2}{|c|}{ Pitch angle curve } & & Sinusoidal curve & $\begin{array}{c}\text { Close to a sinusoidal } \\
\text { curve }\end{array}$ & $\begin{array}{l}\text { Combination of two } \\
\text { trigonometric functions }\end{array}$ \\
\hline \multicolumn{2}{|c|}{ Designed effect } & & $\begin{array}{c}\text { The largest growth is } \\
\text { limited in azimuths of } \\
90^{\circ} \text { and } 270^{\circ}\end{array}$ & $\begin{array}{l}\text { The largest growth is } \\
\text { limited in azimuths } \\
\text { near } 90^{\circ} \text { or } 270^{\circ}\end{array}$ & $\begin{array}{l}\text { The largest values will } \\
\text { distribute at four zones on } \\
\text { two sides of } 90^{\circ} \text { and } 270^{\circ}\end{array}$ \\
\hline
\end{tabular}

of the turbine in the streamtubes and treats each of the two blade elements defined by a given streamtube as an actuator disk. A streamtube of this type is illustrated in Fig. 10 (Paraschivoiu et al., 2009), showing the values of the velocity of the flow at key positions along it. In the figure, "disk 1" represents the upwind blade element and "disk 2" represents the downwind blade element.

The actuator disk theory is based on the momentum conservation; therefore, the velocities of the wind must be known to compute the force acting on the disks. The different values of the local upwind velocity $V$, the equilibrium velocity $V_{\mathrm{e}}$, the downwind velocity $V^{\prime}$, and the free stream velocity $V_{\infty}$, displayed in Fig. 10, can be expressed by the following equations (Islam et al., 2008):

$$
\begin{gathered}
V=a_{\mathrm{up}} V_{\infty}, \\
V_{e}=\left(2 a_{\mathrm{up}}-1\right) V_{\infty}, \\
V^{\prime}=a_{\mathrm{dw}}\left(2 a_{\mathrm{up}}-1\right) V_{\infty},
\end{gathered}
$$

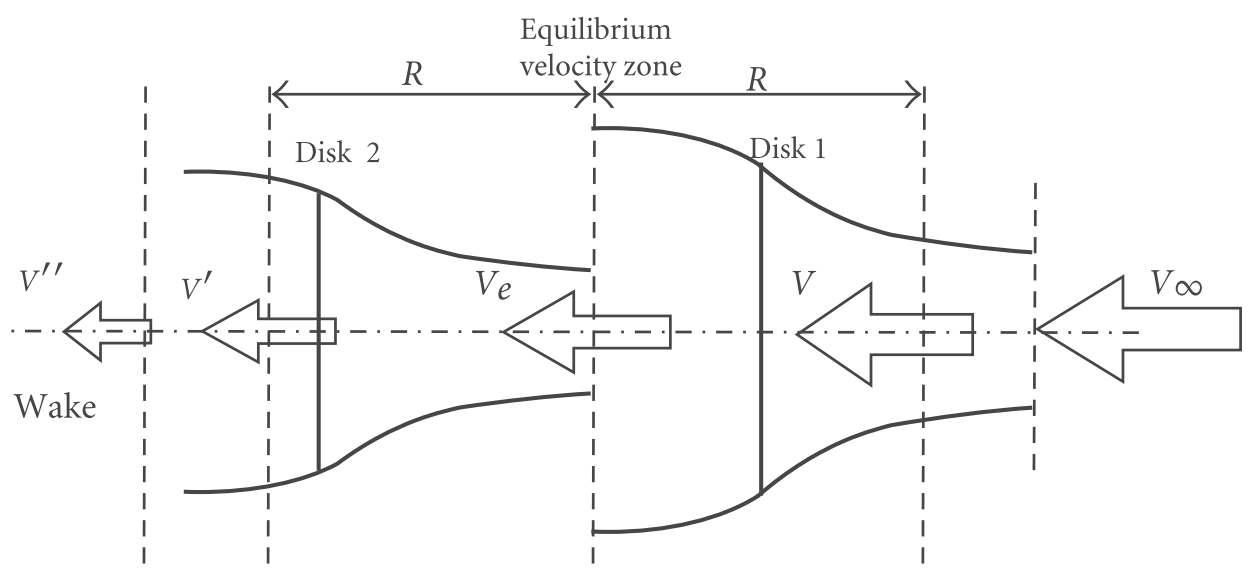

Downwind zone Wind turbine axis Upwind zone

FIG. 10. Figuration of the DMST model (Paraschivoiu et al., 2009). Reprinted with permission from I. Paraschivoiu et al., Int. J. Rotating Mach. 2009, 505343. Copyright 2009 Author(s), licensed under a Creative Commons Attribution 3.0 Unported License. 
where $a_{\mathrm{up}}$ and $a_{\mathrm{dw}}$ are the axial induction factors in the upwind and the downwind regions, respectively,

$$
\begin{gathered}
V_{\mathrm{r} \cdot *}=V_{*} \sqrt{\left(\lambda_{0 \cdot *}-\sin \theta\right)^{2}+\cos ^{2} \theta \cos ^{2} \delta}, \\
\alpha_{*}=\arcsin \left[\frac{\cos \theta \cos \delta}{\sqrt{\left(\lambda_{0 \cdot *}-\sin \theta\right)^{2}+\cos ^{2} \theta \cos ^{2} \delta}}\right],
\end{gathered}
$$

where symbol "*" means the subscripts of "up" or "dw" which represent the upwind half-circle or the downwind half-circle, respectively; $V_{\mathrm{r} \cdot *}$ is the local resultant velocity, $V_{\mathrm{r} \cdot *}=V_{\mathrm{r} \text {.up }}$ in the upwind zone, and $V_{\mathrm{r} \cdot *}=V_{\mathrm{r} \cdot \mathrm{dw}}$ in the downwind zone; $V_{*}$ is the upcoming wind velocity, $V_{\text {up }}=V_{\infty}$, and $V_{\mathrm{dw}}=V_{\mathrm{e}} ; \lambda_{0 \cdot *}$ represents the local TSR, $\lambda_{0 \text {.up }}=r \omega / V_{\infty}$, and $\lambda_{0 \cdot \mathrm{dw}}=r \omega / V_{\mathrm{e}} ; \theta$ is the azimuth angle; $\delta$ is the tilt angle of the blade: it is a variable value in the $\Phi$-type VAWT but is $0^{\circ}$ in the H-type VAWT; and $\alpha_{*}$ is the local AoA (Islam et al., 2008).

In our study, to determine the induction factors, a second set of equations derived from the blade element theory were combined with those of the momentum theory, which were implemented in each semistreamtube (Saeidi et al., 2013). Each blade was subdivided into several elemental sections for which lift and drag coefficients were obtained from experimental measurements. The lift and drag coefficients, $C_{\mathrm{L}}$ and $C_{\mathrm{D}}$, for a given aerofoil section were manipulated to provide the non-dimensional normal and tangential forces,

$$
\begin{aligned}
& C_{\mathrm{N}}=C_{\mathrm{L}} \cos \alpha+C_{\mathrm{D}} \sin \alpha, \\
& C_{\mathrm{T}}=C_{\mathrm{L}} \sin \alpha-C_{\mathrm{D}} \cos \alpha,
\end{aligned}
$$

where $C_{\mathrm{N}}$ and $C_{\mathrm{T}}$ are the normal force and tangential force coefficients, respectively, and $C_{\mathrm{L}}$ and $C_{\mathrm{D}}$ are the lift and drag coefficients, respectively.

Both the resultant velocity and AoA are the functions of the velocity induction factor " $a$ " for a given TSR. By combining the blade element theory and the momentum theory for each streamtube, the induction factor, $a$, can be calculated from

$$
f_{*} a_{*}=\pi \eta\left(1-a_{*}\right),
$$

where $\eta=r / R$ is the dimensionless parameter of the radius, and $f_{*}$ is given by

$$
f_{*}=\frac{N c}{8 \pi R} \int_{0}^{\pi}\left(C_{\mathrm{N}} \frac{\cos \theta}{|\cos \theta|}-C_{\mathrm{T}} \frac{\sin \theta}{|\cos \theta| \cos \delta}\right)\left(\frac{V_{\mathrm{r} \cdot *}}{V_{\infty}}\right)^{2} d \theta,
$$

where $N$ is the number of blades and $c$ is the chord length.

The normal force, $F_{\mathrm{N}}$, and the tangential force, $F_{\mathrm{T}}$, are components of the resultant force of the turbine and are calculated from

$$
\begin{aligned}
& F_{\mathrm{N}}(\theta)=\left(\frac{c H}{S}\right) \int_{-1}^{1} C F_{\mathrm{N}}(\xi) d \xi, \\
& F_{\mathrm{T}}(\theta)=\left(\frac{c H}{S}\right) \int_{-1}^{1} C F_{\mathrm{T}}(\xi) d \xi,
\end{aligned}
$$

where $C F_{\mathrm{N}}(\xi)=C_{\mathrm{N}}\left(V_{\mathrm{r} \cdot *} / V_{\infty}\right)^{2}(\eta / \cos \delta)$ and $C F_{\mathrm{T}}(\xi)=C_{\mathrm{T}}\left(V_{\mathrm{r} \cdot *} / V_{\infty}\right)^{2}(\eta / \cos \delta) ; \quad \xi$ is the dimensionless parameter of the height, $H$ is the height of the turbine, and $S$ is the swept area of the wind turbine.

The upwind or downwind disk contribution to total torque can be obtained by summing the moments of the tangential component of resultant force about the turbine center for each streamtube, 


$$
\begin{gathered}
M_{*}(\theta)=\frac{1}{2} \rho c R H \int_{-1}^{1} C_{\mathrm{T}} V_{\mathrm{r} \cdot *}^{2}(\eta / \cos \delta) d \xi \\
\bar{M}_{*}=\frac{N}{2 \pi} \int_{0}^{\pi} M_{*}(\theta) d \theta \\
\bar{C}_{\mathrm{M} \cdot *}=\bar{M}_{*} /\left(\frac{1}{2} \rho V_{\infty}^{2} S R\right)=\frac{N c H}{2 \pi S} \int_{0}^{\pi} \int_{-1}^{1} C_{\mathrm{T}}\left(\frac{V_{\mathrm{r} \cdot *}}{V_{\infty}}\right)^{2}\left(\frac{\eta}{\cos \delta}\right) d \xi d \theta \\
C_{\mathrm{P} \cdot *}=\lambda_{0 \cdot *} \bar{C}_{\mathrm{M}},
\end{gathered}
$$

where $M_{*}(\theta)$ is the local torque value, $\rho$ is the air density, and $\bar{M}_{*}$ is the average value of the local torque. $\bar{C}_{\mathrm{M} \cdot *}$ is the average value of torque coefficient, and $C_{\mathrm{P} \cdot *}$ is the power coefficient.

This process is computed for the upwind zone in the given free stream velocity of $V_{\infty}$ and repeated for the downwind sections with the equilibrium velocity, given by Eq. (5), considered as the free stream velocity for the second actuator disk in the downwind section of the streamtube.

Adding up the power coefficients in the upwind disk, $C_{\mathrm{P} \text {.up }}$, and in the downwind disk, $C_{\mathrm{P} \cdot \mathrm{dw}}$, the total power coefficient $C_{\mathrm{P} \cdot \mathrm{t}}$ obtained for one cycle is

$$
C_{\text {P.t }}=C_{\text {P.up }}+C_{\text {P.dw }} .
$$

\section{B. Tip loss consideration}

The effect of the tip loss was considered in the modeling. Tip loss characterizes the tendency for trailing the vorticity from the tip of a wind turbine blade or from any other point where the circulation distribution changes, thereby reducing the blade's effectiveness. Prandtl's tip loss factor is commonly used for VAWTs (Soraghan et al., 2013),

$$
F=\frac{2 \arccos \left(e^{-\pi\left(\frac{H}{2}-|z|\right) / b}\right)}{\pi},
$$

where $Z$ is the height of the streamtube away from the equatorial position; the coefficient of $b$ in the upwind and downwind disks is expressed as follows:

$$
\begin{gathered}
b=\frac{\pi V_{\mathrm{e}}}{N \omega}=\frac{\pi V_{\infty}\left(1-2 a_{\mathrm{up}}\right)}{N \omega}, \\
b=\frac{\pi V_{\mathrm{e}}\left(1-2 a_{\mathrm{dw}}\right)}{N \omega} .
\end{gathered}
$$

AoA after correction is expressed as follows:

$$
\alpha=\arctan \left(\frac{F U \sin \theta}{U \cos \theta+\omega r}\right) .
$$

The corrected resultant velocity is

$$
V_{\mathrm{r}}=\sqrt{(\omega r+U \cos \theta)^{2}+(F U \sin \theta)^{2}},
$$

where $U$ is the stream velocity in the streamtube, in the upwind tube $U=V$, and in the downwind tube $U=V^{\prime}$.

H-type VAWTs have a large aspect ratio blade, whose circular distribution in spanwise is assumed as aplitic-shape. Therefore, the corrected lift coefficient and drag coefficient are given as follows: 


$$
\begin{gathered}
C_{\mathrm{L} . \mathrm{f}}=\frac{C_{\mathrm{L}}}{1+C_{\mathrm{L} . \mathrm{a}} / \varsigma}, \\
C_{\mathrm{D} . \mathrm{f}}=C_{\mathrm{D}}+C_{\mathrm{L} . \mathrm{f}}^{2} / \varsigma,
\end{gathered}
$$

where $C_{\mathrm{L} . \mathrm{f}}$ and $C_{\mathrm{D} . \mathrm{f}}$ are the corrected lift coefficient and drag coefficient; $C_{\mathrm{L} . \mathrm{a}}$ is the slope of the lift coefficient curve; and $\varsigma$ is the aspect ratio of the blade.

\section{MODEL VALIDATION}

The discussed DMST model is programmed using MATLAB routines. To calculate induction factors $a_{\mathrm{up}}$ or $a_{\mathrm{dw}}$, an iterative method is used. The upstream induction factor $a_{\text {up }}$ is initially set to be zero. Applying Eqs. (7), (8), (9), and (10) and substituting in (12) determine $f_{*}$, and a new induction factor $a_{*}$ is then calculated from (11). This procedure is repeated iteratively to calculate a new induction factor $\left(a_{\text {up }}\right.$ or $\left.a_{\mathrm{dw}}\right)$ until the difference between two consecutive values converges to an error band of less than 0.0001 .

The DMST model has been widely used for the prediction of the aerodynamic performance of lifts in VAWTs, and the results have confirmed that the model can provide acceptable accuracy. In this paper, the model validation was used to verify the correction of the program process rather than to test the accuracy of the mathematical model. Extensive experimental data in the available literature are for the $\Phi$-type VAWTs, whereas scarce information has been published about H-type turbines. Thus, we chose a two-bladed $\Phi$-type Darrieus turbine tested in the Sandia National Laboratories, USA, for validation. The turbine has a height of $2 \mathrm{~m}$, a rotation diameter of $2 \mathrm{~m}$, and a chord length of $0.09 \mathrm{~m}$ and employs the NACA0012 airfoil. Tests and measurements of the power coefficient versus TSR were conducted in the wind tunnel at constant wind velocities of $7 \mathrm{~m} / \mathrm{s}$ and $9 \mathrm{~m} / \mathrm{s}$, respectively (Strickland, 1975). As can be seen in Fig. 11(a), the modeling results are consistent with the experimental results, which confirms the correctness of the program process. In addition, Paraschivoiu and Delclaux (1983) employed DMST to predict the performance of H-type VAWT employing NACA0015 aerofoil. As depicted in Fig. 11(b), the two computational results agree well with each other, which once again evidences that the program is correct. All the aerodynamics data of aerofoil are from the reference study published by Sheldahl and Klimas (1981).

\section{RESULTS AND ANALYSIS}

The curve of the pitch angle versus azimuth was designed based on an H-type VAWT rotating in the optimum TSR $=5.0$. Its structure parameters are as follows: a height of $2 \mathrm{~m}$, a rotation diameter of $2 \mathrm{~m}$, and a chord length of $0.09 \mathrm{~m}$, and it employs NACA0012 airfoil, which are almost the same as those of the Sandia turbine except the parameter of the tilt angle depending on the curve of the blade. Then, the performance in three TSRs, 4.5, 5.0, and 5.5 was modeled using the DMST mathematical model.

\section{A. Angle of attack (AoA)}

The 3D figures represent the distribution of AoA in the whole swept area of the blade (Fig. 12). It is obvious that the AoA at the blade tip is zero because the tip loss causes a much lower (even zero) velocity of the flow across the aerofoil than that of the spanwise one. Under FP-VAWT conditions, whether in the upwind or the downwind region, the AoA appears to be in a parabolic shape; the max values obtained are at an azimuth of $90^{\circ}$ in the upwind zone and at an azimuth of $270^{\circ}$ in the downwind zone. At a certain height exclusive of two tips of the blade, the curve of AoA becomes similar to a sinusoidal function, which is identical to the result of the theoretical analysis [Figs. 12(a), 12(c), and 12(e)].

Under VP-VAWT conditions, the shape of AoA changes into trapezoid in the upwind region, which means that the maximum values do not only locate at $90^{\circ}$ any more but also in a much wider azimuth zone. It should be emphasized that the maximum AoAs have little change 


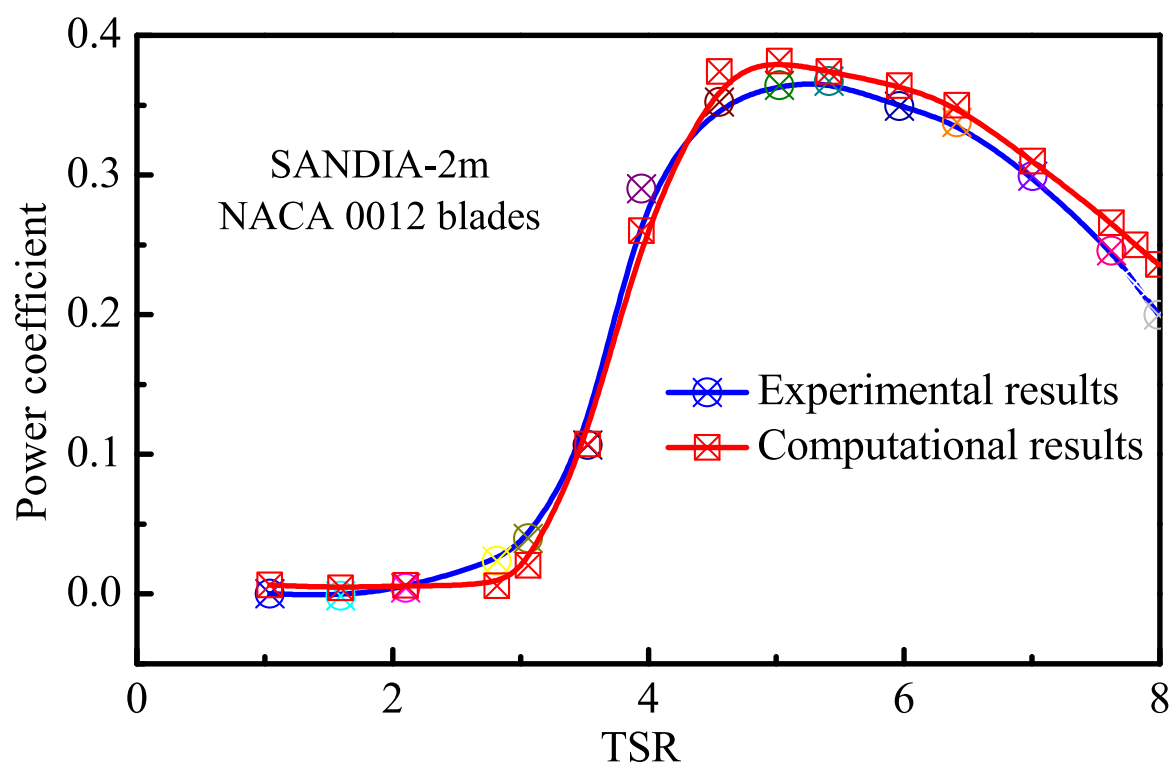

(a)

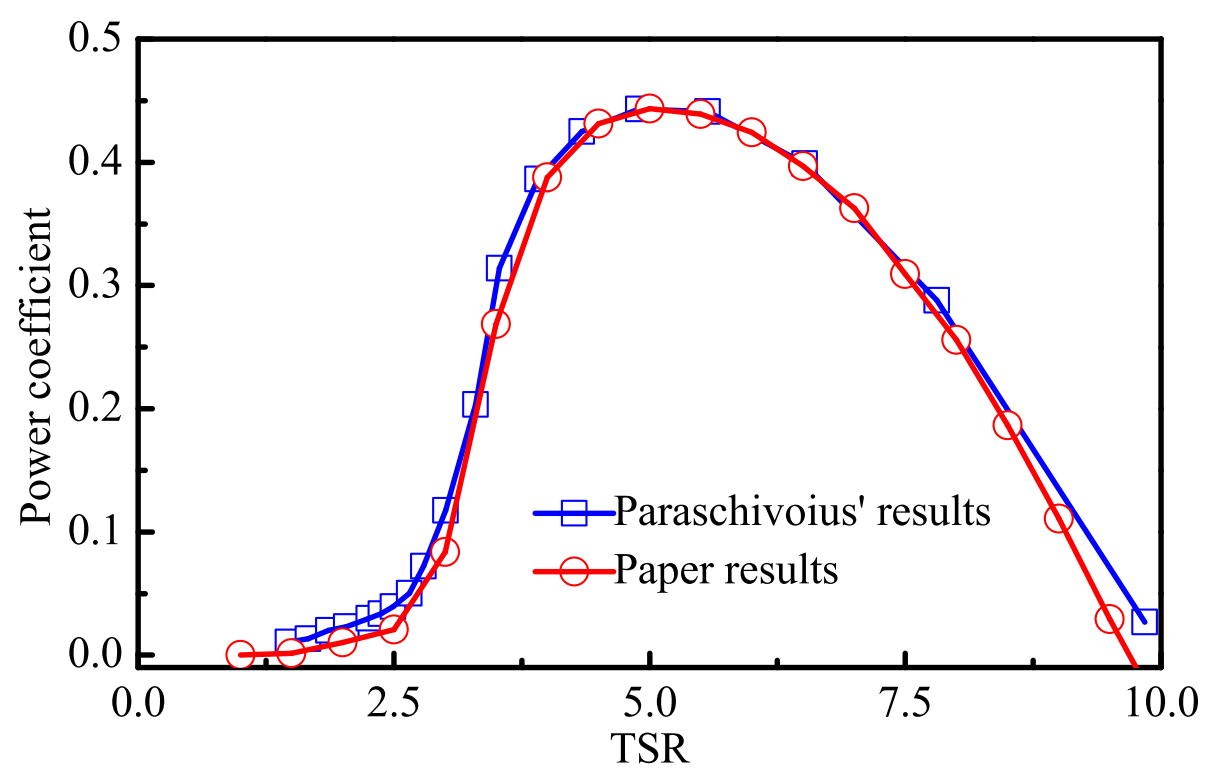

(b)

FIG. 11. Model validation: (a) comparison between computational results and experimental results and (b) comparison between Paraschivoiu's results and our results.

in contrast to those of the FP-VAWT. Small decreases are observed in this parameter with the increase in TSR, which is caused by increasing resultant velocity.

As shown in Figs. 12(b), 12(d), and 12(f), the distribution of AoA appears in a "W" shape in the downwind region of VP-VAWT. The maximum negative AoAs newly created on the two sides of the $270^{\circ}$ azimuth are larger than that in FP-VAWT. Both the pitch angle and the varied upcoming wind velocity contribute to these changes. Doubtless, the VP-strategy increases the AoA in the upwind region. On the other hand, according to the energy conservation law, the upcoming wind velocity of the blade in the downwind region is decreased because more wind energy is extracted in the upwind region of VP-VAWT than in that of FP-VAWT, which results in a smaller wind velocity in their wake. Therefore, the VP-technology contributes mainly to an increase in AoA, which causes performance enhancement of VAWT. 


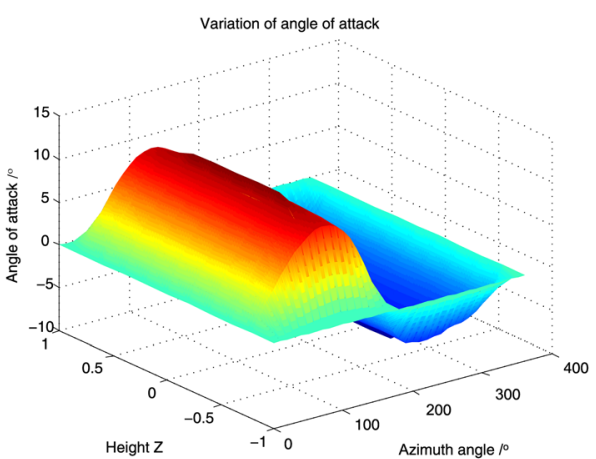

(a)

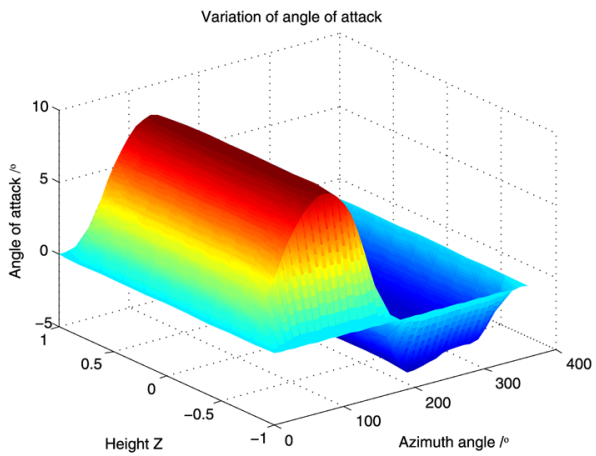

(c)

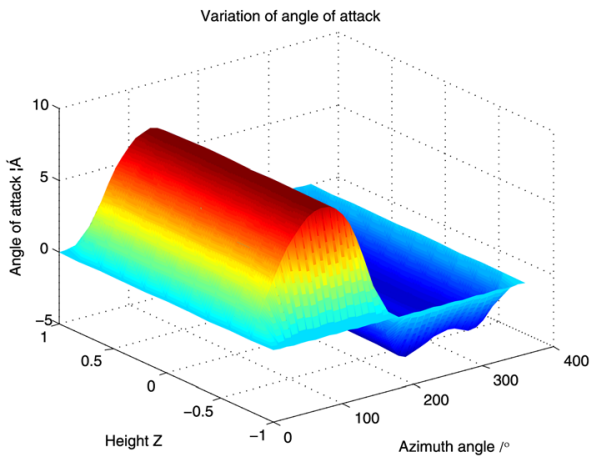

(e)

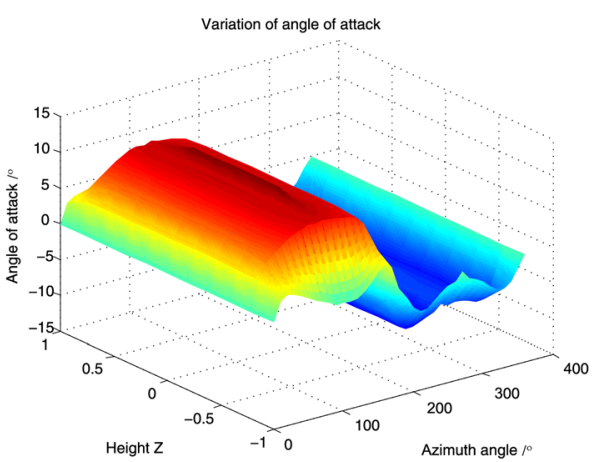

(b)

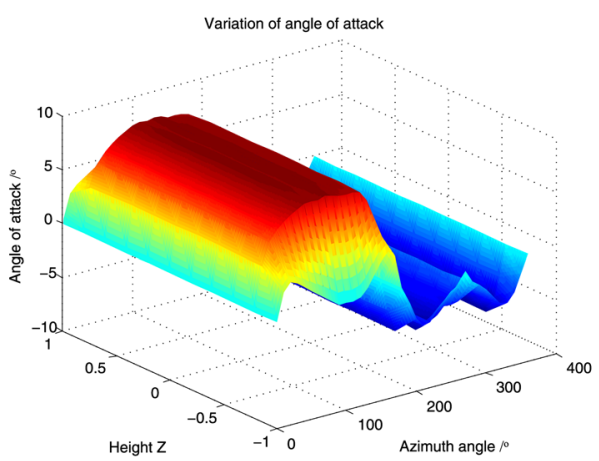

(d)

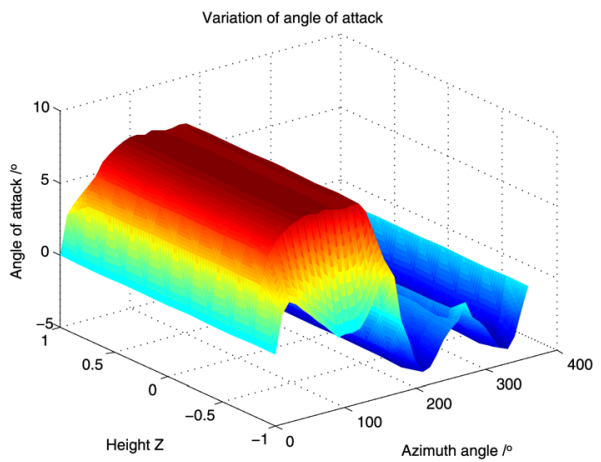

(f)

FIG. 12. Distribution of AoA: (a) TSR=4.5, FP-VAWT; (b) TSR=4.5, VP-VAWT; (c) TSR=5, FP-VAWT; (d) $\mathrm{TSR}=5$, VP-VAWT; (e) TSR = 5.5, FP-VAWT; and (f) TSR = 5.5, VP-VAWT.

\section{B. Tangential force coefficient}

The lift generated by the blade has a tangential component in the direction of rotation which directly drives the blade to rotate. Thus, a higher tangential force would increase the power output of the turbine under the condition of a constant angular speed. The tangential force coefficient is a non-dimensional factor which can reflect the degree of the tangential force and facilitates the comparison between different turbines.

As shown in Figs. 13(a), 13(c), and 13(e), in the FP-VAWT, the highest tangential force is mainly located near the azimuth of $90^{\circ}$ in the upwind region. Similar to AoA, the tangential force appears as a parabolic configuration. As the TSR increases, the maximal value of the tangential force coefficient decreases. This change is affected by two factors: the resultant velocity and AoA. The increase in TSR leads to elevation of the resultant velocity, whereas AoA declines. The effect of the growth of the resultant velocity is smaller than that of the reduction of AoA, which results in obtaining a smaller tangential force in larger TSR. The tangential 


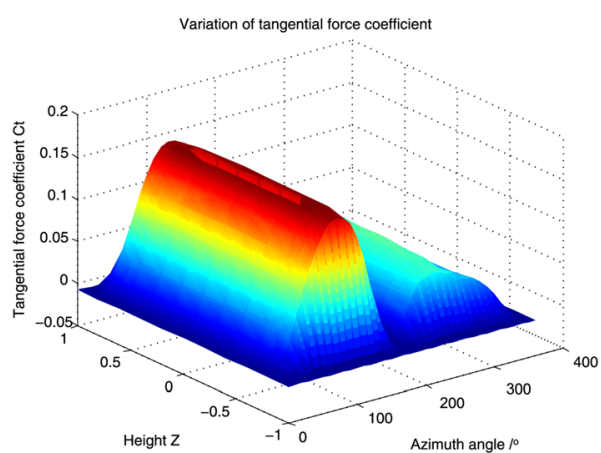

(a)

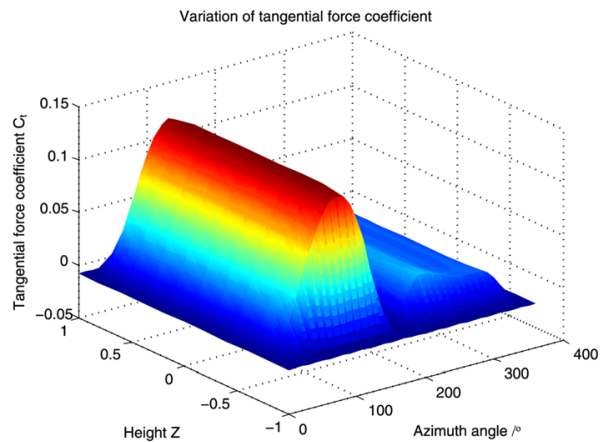

(c)

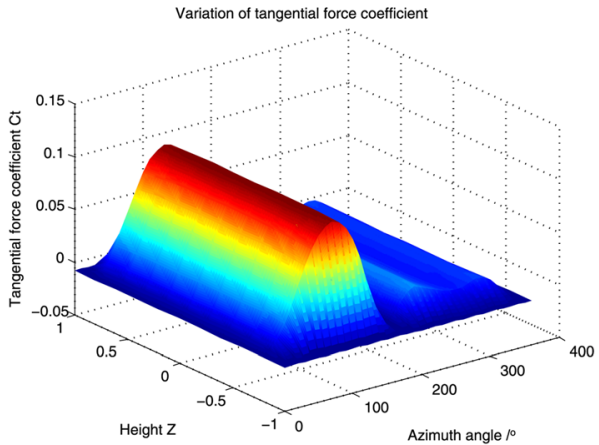

(e)

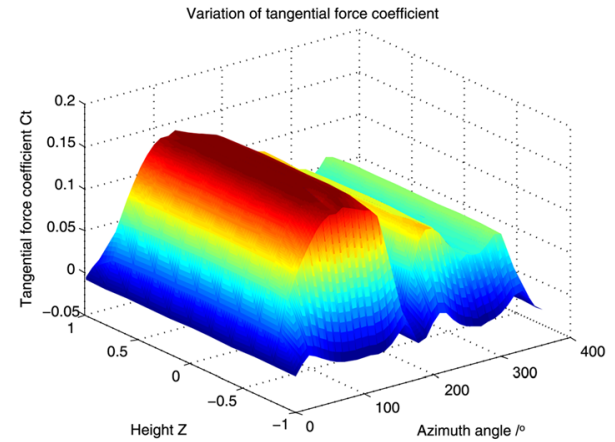

(b)

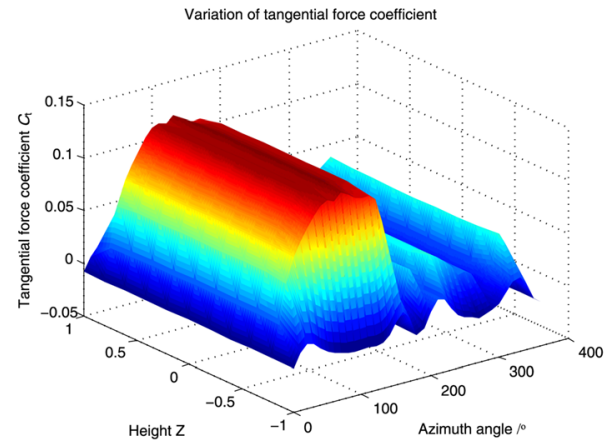

(d)

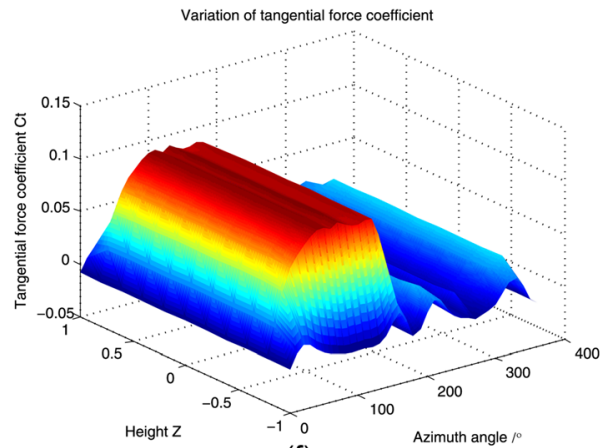

(f)

FIG. 13. Distribution of the tangential force coefficient: (a) TSR $=4.5$, FP-VAWT; (b) TSR $=4.5$, VP-VAWT; (c)TSR $=5$, FP-VAWT; (d) TSR = 5, VP-VAWT; (e) TSR = 5.5, FP-VAWT; and (f) TSR = 5.5, VP-VAWT.

forces in the downwind half-circle, including the maximum value, are lower compared to those in the upwind region and decline further with the increase in TSR.

As seen in Figs. 13(b), 13(d), and 13(f), due to the impact of AoA on the blade in VPVAWT, the tangential force distribution exhibits a trapezoidal shape and a wider azimuth zone with the largest values achieved in the upwind half-circle; the maximum value remains the same as that of the FP-turbine. Following the tendency displayed in FP-VAWT, the increase in TSR leads to a decrease in the maximum value of the tangential force coefficient. In the downwind half-circle, the growth is obvious when TSR $=4.5$, with two new maximal values of tangential force which make the whole shape obtain an M-like appearance. The value decreases with the increase in TSR, but the growth compared to that in the FP-case is still larger.

\section{Normal force coefficient}

As depicted in Fig. 14, which displays the distribution of the normal force coefficient in the whole circular path, the differences between the FP- and VP-VAWT are exceedingly similar 


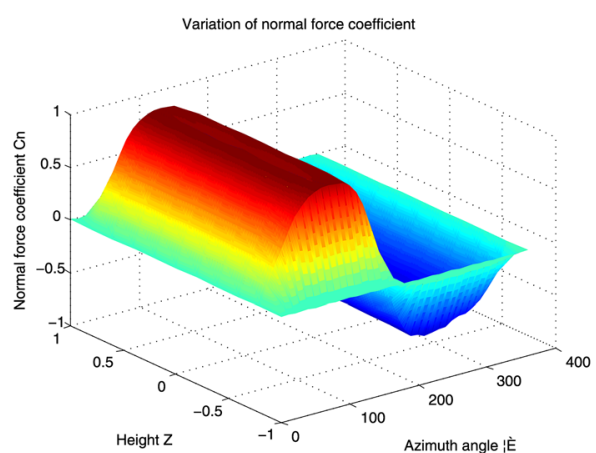

(a)

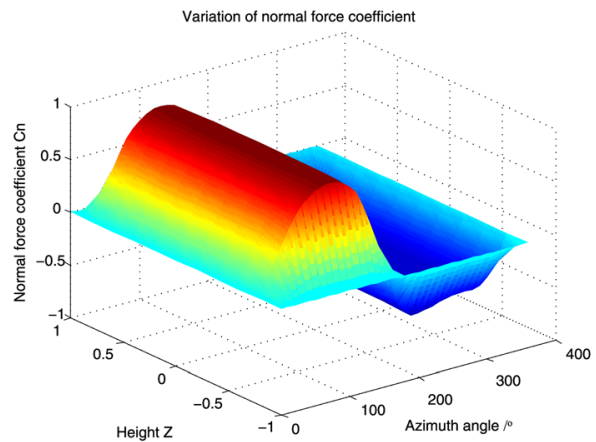

(c)

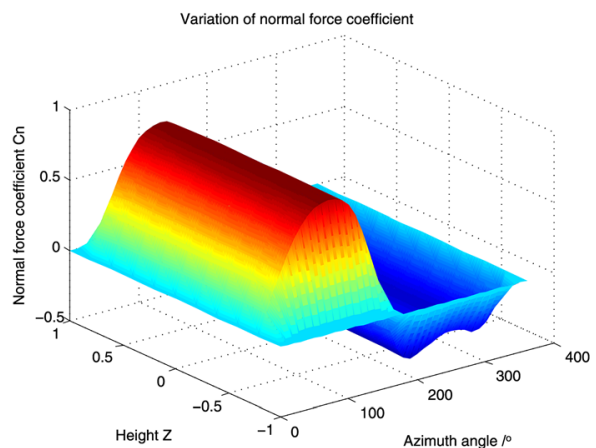

(e)

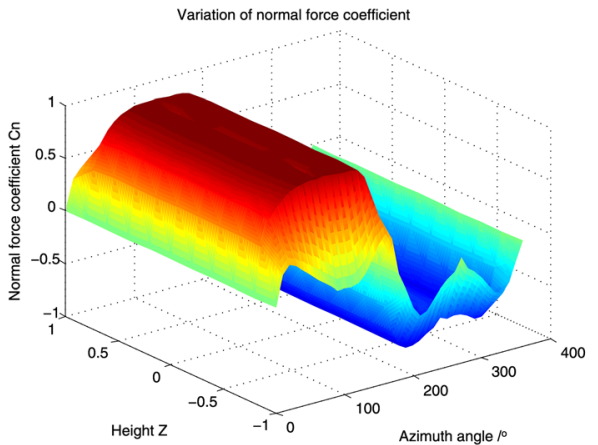

(b)

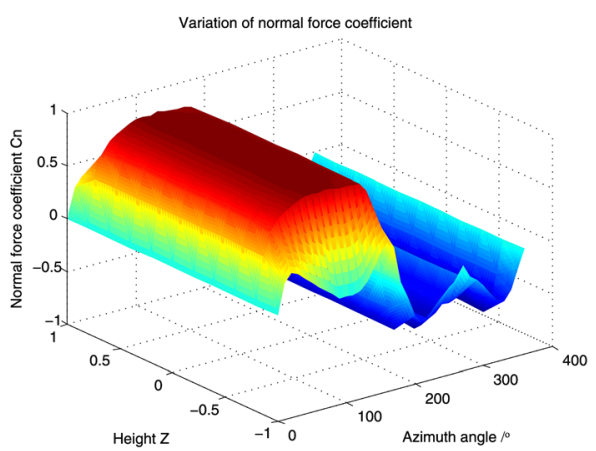

(d)

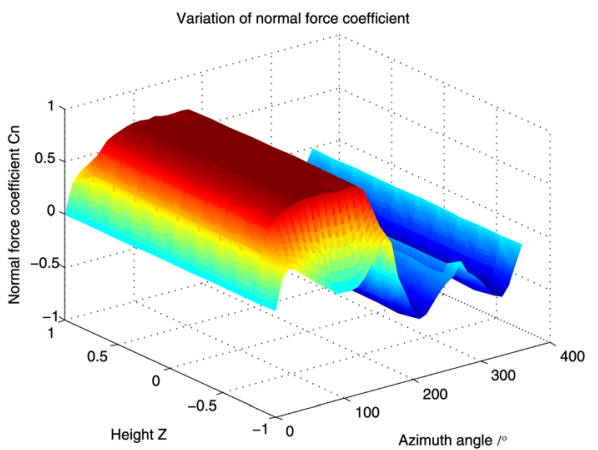

(f)

FIG. 14. Distribution of the normal force coefficient: (a) TSR $=4.5$, FP-VAWT; (b) TSR $=4.5$, VP-VAWT; (c) TSR $=5$, FP-VAWT; (d) TSR =5, VP-VAWT; (e) TSR $=5.5$, FP-VAWT; and (f) TSR $=5.5$, VP-VAWT.

to those of AoA, presented in Fig. 12. Importantly, the VP-technology widens the maximum normal force zone in the upwind region and creates two new maximum negative forces. In addition, with the increase in TSR, these phenomena become even more obvious. The direction of the normal force to the circle path of the VAWT blade is vertical and does not affect the power output but is closely related to the stability of the structure. The new VP-technology reduces the normal force changes, which is extremely helpful in the decrease of structural vibration.

\section{Power}

Figure 15 provides the power distribution among the whole swept area of VAWT. Its value is the sum of the power of two corresponding half-streamtubes in the upwind and downwind half-circles. Thus, Fig. 15 illustrates the comprehensive effect of the VP-technology on the upwind and the downwind disks. 


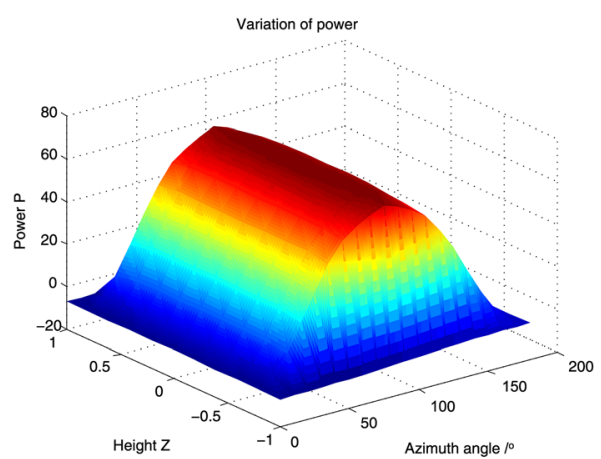

(a)

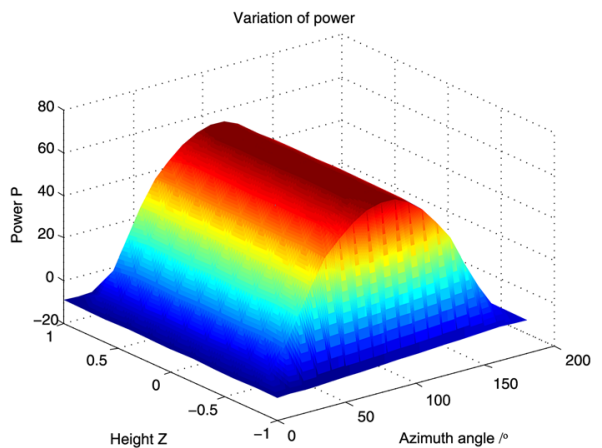

(c)

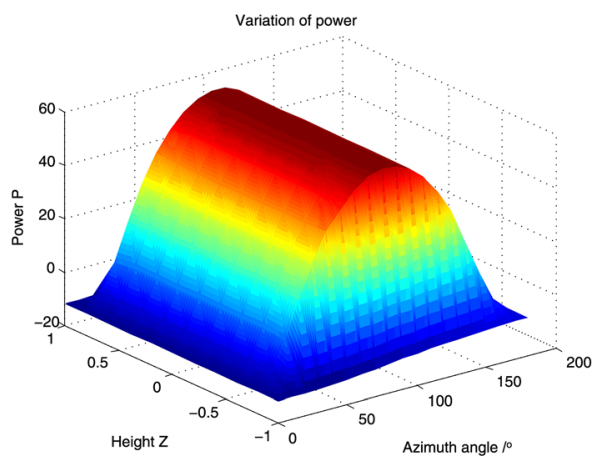

(e)

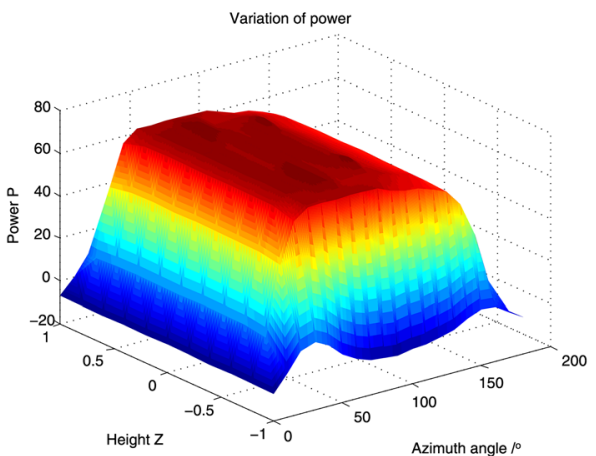

(b)

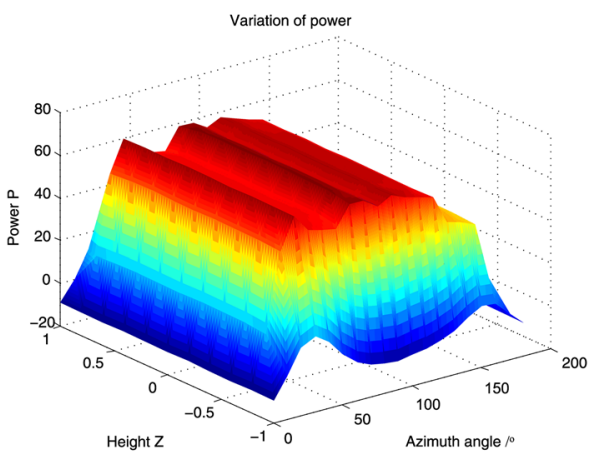

(d)

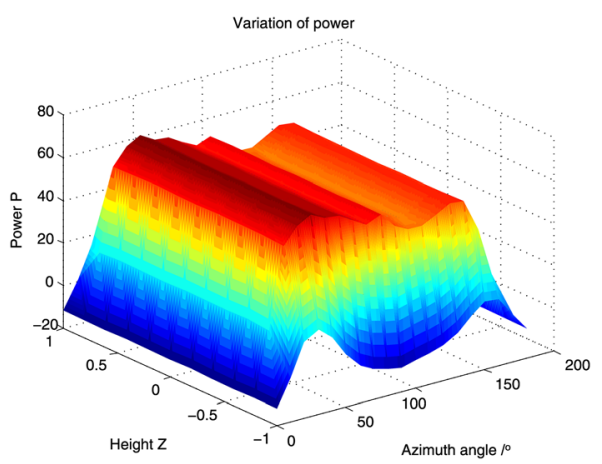

(f)

FIG. 15. Distribution of power: (a) TSR=4.5, FP-VAWT; (b) TSR=4.5, VP-VAWT; (c) TSR=5, FP-VAWT; (d) $\mathrm{TSR}=5$, VP-VAWT; (e) TSR $=5.5$, FP-VAWT; and (f) TSR $=5.5$, VP-VAWT .

As shown in Figs. 15(a), 15(c), and 15(e), a max power is produced at the azimuth of $90^{\circ}$ and two negative power zones are produced at neighboring $0^{\circ}$ and $180^{\circ}$ azimuths. The overall power output is the integration of the curved surface along the " $\mathrm{Z}$ " axis and azimuth. Compared with the FP-VAWT, the new VP-VAWT achieves a significant improvement in power performance. In the FP-VAWT, the power output exhibits an arch distribution, and the output is relatively large only in an exceedingly small zone. In the VP-VAWT, the power output distribution to a considerable extent approximates a rectangular shape, in which the zone with high performance is markedly widened, whereas the zone adjacent to $0^{\circ}$ and $180^{\circ}$ azimuths with lower performance is greatly narrowed. The increase in TSR leads to changes in the power output distribution in VP-VAWT. First, the maximum value is decreased slightly with the increase in TSR. The larger the TSR is the smaller the AoA is, which leads to a smaller power. Second, the distribution of the high power value fluctuates more significantly 


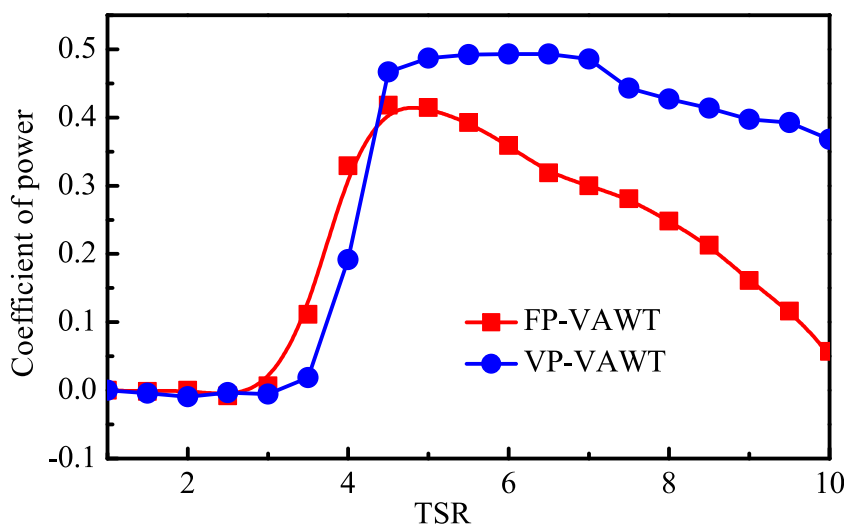

FIG. 16. Curves of the power coefficient of FP- and VP-VAWT.

with the augmentation of TSR. This is caused by the changes in the performance of the downwind disk (Figs. 11-13).

A comparison the curves of the power coefficient between the two turbines shows that the VP-VAWT obviously has larger efficiency when TSR $>4.5$. The wider zone of the maximum power in the swept area of VP-VAWT causes the larger power coefficient. The growth of the power coefficient has reached $18.9 \%$ in TSR $=5$ and is getting larger as TSR grows (Fig. 16). The coefficient of VP-VAWT is smaller than that of FP-VAWT as TSR $<4.5$. The reason is that the curve of the pitch angle designed in TSR $=5$ also increases AoA at smaller TSR, and the larger AoA may lead to stall happening easily in the upper surface of the blade, which makes the turbine obtain a lower power coefficient in smaller TSR. Figure 16 also shows that the new VP-technology widens the highest performance zone, which makes the turbines capable of running with high efficiency in wider TSR zones.

\section{CONCLUSIONS}

Contrary to the concept reflected in most of the recent publications, herein, we propose a new VP-strategy that focuses mainly on aerodynamics improvement at the azimuth with the low performance in the case of maintaining the zero pitch angles in four specific azimuths $\left(0^{\circ}\right.$, $90^{\circ}, 180^{\circ}$, and $270^{\circ}$ ). The research was conducted based on the DMST model, and the tip loss was evaluated by Prandtl's mathematics. The following changes have been made in the new VP-VAWT compared to FP-VAWT and are summarized in Table II:

TABLE II. Final effect of the new VP-approach.

\begin{tabular}{|c|c|c|c|c|}
\hline \multicolumn{3}{|l|}{ Comparison items } & \multirow[t]{2}{*}{ FP-VAWT } & VP-VAWT(Author) \\
\hline AoA & Upwind region & Shape of distribution & & Trapezoid like shape \\
\hline & & Maximal value & Only one position & A wide zone \\
\hline & Downwind region & Shape of distribution & A upward parabolic shape & W-like shape \\
\hline & & Maximal value & Only one position & Two new bigger maximal ones \\
\hline \multirow[t]{4}{*}{ Tangential Force } & Upwind region & Shape of distribution & A downward parabolic shape & Trapezoid like shape \\
\hline & & Maximal value & Only one position & A wide zone \\
\hline & Downwind region & Shape of distribution & A downward parabolic shape & M-like shape \\
\hline & & Maximal value & Only one position & Two new bigger maximal ones \\
\hline \multirow[t]{2}{*}{ Power } & Swept area of turbine & Shape of distribution & arched shape & Rectangular shape \\
\hline & & Maximal value & Only one position & A wide zone \\
\hline Power coefficient & & & & $18.9 \%$ growth at $\mathrm{TSR}=5$ \\
\hline
\end{tabular}


(1) In the upwind region of VP-VAWT, the distribution of AoA changes from a parabolic to trapezoid shape, and the maximum AoA is not changed nor limited to a position but a wide azimuth zone. Two new maximum values are created in the downwind disk, and the whole distribution appears as a "W" shape.

(2) In the upwind region of VP-VAWT, due to the impact of AoA, the maximum tangential force is distributed in a much wider zone than that in FP-VAWT, and the trapezoidal shape appears. In the downwind region, the distribution obtains an M-like shape due to the two newly created maximum values, which are larger than those at the azimuth angle of $270^{\circ}$ in FP-VAWT.

(3) In VP-VAWT, the normal force changes follow the tendency of the variations in AoA. A smaller change in the normal force in the whole circle path makes the structure more stable and considerably reduces vibration.

(4) Power distribution changes from an arched shape into a rectangular shape, and the vicinity zones with poor performance near $0^{\circ}$ and $180^{\circ}$ are greatly narrowed, whereas the zone with high performance is markedly widened. With the increase in TSR, this tendency is not changed, and the max value is decreased.

(5) The new VP-approach greatly widens the high performance azimuth zone of a single blade and effectively reduces the effect of small AOA. Consequently, an $18.9 \%$ growth in power efficiency is achieved. The new VP-approach also widens the highest performance TSR zone which makes the turbines capable of running with high efficiency in wider zones.

\section{ACKNOWLEDGMENTS}

This paper was supported by the project of the National Natural Science Foundation of China under Grant No. 11502070, the National Basic Research Program of China ("973" Program) under Project No. 2014CB046200, and "Summit of the Six Top Talents" Program of Jiangsu Province under Project No. XNY-007.

\section{NOMENCLATURE}

\section{Roman letters}

a Induction factor (-)

$A_{\mathrm{c}} \quad$ Amplitude of the pitch angle (deg)

$A_{\mathrm{s}} \quad$ Max amplitude of the pitch angle (deg)

AoA Angle of attack (deg)

$c \quad$ Length of chord line $(\mathrm{m})$

$C_{\mathrm{D}} \quad$ Drag coefficient (-)

$C_{\mathrm{L}} \quad$ Lift coefficient (-)

$C_{\mathrm{M}} \quad$ Torque coefficient (-)

$C_{\mathrm{N}} \quad$ Normal force coefficient (-)

$C_{\mathrm{P}} \quad$ Power coefficient (-)

$C_{\mathrm{T}} \quad$ Tangential force coefficient (-)

CFD Computational fluid dynamics (-)

DMST Double multi streamtube (model)

$F_{\mathrm{N}} \quad$ Tangential force $(\mathrm{N})$

$F_{\mathrm{T}} \quad$ Normal force $(\mathrm{N})$

FP Fixed pitch (-)

$h \quad$ Height of blade element (m)

$H \quad$ Height of rotor (m)

HAWT Horizontal axis wind turbine (-)

$M \quad$ Torque of blade ( $\mathrm{N} \mathrm{m})$

$N \quad$ Number of blade (-)

$p \quad$ Power of rotor $(\mathrm{kW})$

$r \quad$ Rotation radius of blade element (m) 
$R \quad$ Equatorial radius of rotor (m)

$S \quad$ Swept area of wind rotor $\left(\mathrm{m}^{2}\right)$

TSR Tip speed ratio (-)

$U \quad$ Tangential velocity $(\mathrm{m} / \mathrm{s})$

$V \quad$ Velocity in upwind tube $(\mathrm{m} / \mathrm{s})$

$V^{\prime} \quad$ Velocity in downwind tube $(\mathrm{m} / \mathrm{s}]$

$V_{\mathrm{e}} \quad$ Equilibrium velocity $(\mathrm{m} / \mathrm{s})$

$V_{\mathrm{r}} \quad$ Resultant velocity $(\mathrm{m} / \mathrm{s})$

$V_{\infty} \quad$ Free wind velocity $(\mathrm{m} / \mathrm{s})$

VAWT Vertical axis wind turbine (-)

VP Variable pitch (-)

$X_{0} \quad$ TSR of $\max C_{\mathrm{P}}$ at zero $A_{\mathrm{c}}(-)$

\section{Greek letters}

$\alpha$ Angle of attack (deg)

$\gamma \quad$ Pitch angle changed with the azimuth (deg)

$\delta \quad$ Inclination angle of blade element (deg)

$\eta \quad$ Dimensionless parameter of radius (-)

$\varsigma$ Aspect ratio of blade (-)

$\theta \quad$ Azimuth (deg)

$\lambda$ Tip speed ratio (TSR) (-)

$\xi$ Dimensionless parameter of height (-)

$\rho$ Density of air $\left(\mathrm{kg} \mathrm{m}^{-3}\right)$

$\omega$ Rotor angular velocity ( $\mathrm{rad} \mathrm{s}^{-1}$ )

\section{Subscripts}

dw Downwind disk

$\mathrm{N}$ Normal direction

t Total

$\mathrm{T}$ Tangential direction

up Upwind disk

$\infty \quad$ Free wind condition

Bhutta, M. M. A., Hayat N., Farooq, A. U. et al., "Vertical axis wind turbine-A review of various configurations and design techniques,” Renewable Sustainable Energy Rev. 16, 1926-1939 (2012).

Camporealea, S. M. and Magi, V., "Streamtube model for analysis of vertical axis variable pitch turbine for marine currents energy conversion," Energy Convers. Manage. 41, 1811-1827 (2000).

Chougule, P. and Nielsen, S., "Overview and design of self-acting pitch control mechanism for vertical axis wind turbine using multi body simulation approach,” J. Phys.: Conf. Ser. 524, 012055 (2014).

Claessens, M. C., "The design and testing of airfoils in small vertical axis wind turbines," M.S. thesis (Delft University of Technology, Delft, The Netherlands, 2006).

Cooper, P. and Kennedy, O. C., "Development and analysis of a new novel vertical axis wind turbine," in 42nd Annual Conference of the Australian and New Zealand Solar Society, Perth, Australia (2004).

Eboibi, O., Danao, L. A. M., and Howell, R. J., "Experimental investigation of the influence of solidity on the performance and flow field aerodynamics of vertical axis wind turbines at low Reynolds number," Renewable Energy 92, 474-483 (2016).

Elkhoury, M., Kiwata, T., and Aoun, E., "Experimental and numerical investigation of a three-dimensional vertical-axis wind turbine with variable-pitch,” J. Wind Eng. Ind. Aerodyn. 139, 111-123 (2015).

Erickson, D. W., Wallace, J. J., and Peraire, J., "Performance characterization of cyclic blade pitch variation on a vertical axis wind turbine," in 49th AIAA Aerospace Sciences Meeting Including the New Horizons Forum and Aerospace Exposition 4-7 January 2011, Orlando, Florida (2011).

Firdaus, R., Kiwata, T., Kono, T., and Nagao, K., "Numerical and experimental studies of a small vertical-axis wind turbine with variable-pitch straight blades," J. Fluid Sci. Technol. 10(1), 14-29 (2015).

Hantoro, R., Utama, I. K. A. P., Erwandi, E., and Sulisetyono, A., "An experimental investigation of passive variable-pitch vertical-axis ocean current turbine,” ITB J. Eng. Sci. 43(1), 27-40 (2011).

Hwang, I. S., Yun, H. L., and Kim, S. J., "Optimization of cycloidal water turbine and the performance improvement by individual blade control,” Appl. Energy 86(9), 1532-1540 (2009). 
Islam, M., Ting, D. S. K., and Fartaj, A., "Aerodynamic models for Darrieus-type straight-bladed vertical axis wind turbines," Renewable Sustainable Energy Rev. 12, 1087-1109 (2008).

Kirke, B. K., "Evaluation of self-starting vertical axis wind turbines for stand-alone applications," Ph.D. thesis (Griffith University Gold Coast, Brisbane, Australia, 1998).

Kosaku, T., San, M., and Nakatani, K., "Optimum pitch control for variable-pitch vertical-axis wind turbines by a single stage model on the momentum theory," in IEEE International Conference on Systems, Man and Cybernetics, 2002 (IEEE, 2002).

Liu, L. Q., Liu, C. X., and Zheng X. Y., "Modeling, simulation, hardware implementation of a novel variable pitch control for H-type vertical axis wind turbine," J. Electr. Eng. 66(5), 264-269 (2015).

Mertens, S., Wind Energy in the Built Environment: Concentrator Effects of Buildings (TUDelft, 2006).

Mohamed, M., Ali, A., and Hafiz, A., "CFD analysis for H-rotor Darrieus turbine as a low-speed wind energy converter," Eng. Sci. Technol. Int. J. 18(1), 1-13 (2015).

Paraschivoiu, I. and Delclaux, F., "Double multiple streamtube model with recent improvements (for predicting aerodynamic loads and performance of Darrieus vertical axis wind turbines),” J. Energy 7(3), 250-255 (1983).

Paraschivoiu, I., Trifu, O., and Saeed, F., "H-Darrieus wind turbine with blade pitch control," Int. J. Rotating Mach. 2009, 505343.

Pawsey, N. C. K., "Development and evaluation of passive variable-pitch vertical axis wind turbines," Ph.D. thesis (The University of New South Wales, Australia, 2002).

Saeidi, D., Sedaghat, A., Alamdari, P., and Alemrajabi, A. A., "Aerodynamic design and economical evaluation of site specific small vertical axis wind turbines," Appl. Energy 101, 765-775 (2013).

Sagharichi, A., Maghrebi, M. J., and ArabGolarcheh, A., "Variable pitch blades: An approach for improving performance of Darrieus wind turbine," J. Renewable Sustainable Energy 8, 053305 (2016).

Schonborn, A. and Chantzidakis, M., "Development of a hydraulic control mechanism for cyclic pitch marine current turbines," Renewable Energy 32, 662-679 (2007).

Sengupta, A., Biswas, A., and Gupta, R., "Studies of some high solidity symmetrical and unsymmetrical blade H-Darrieus rotors with respect to starting characteristics, dynamic performances and flow physics in low wind streams," Renewable Energy 93, 536-547 (2016).

Sheldahl, R. E. and Klimas, P. C., "Aerodynamic characteristics of seven symmetrical airfoil sections through 180-degree angle of attack for use in aerodynamic analysis of vertical axis wind turbines," Report No. SAND80-2114, 1981.

Shires, A. and Kourkoulis, V., "Application of circulation controlled blades for vertical axis wind turbines," Energies 6, 3744-3763 (2013).

Soraghan, C. E., Leithead, W. E., Feuchtwang, J., and Yue, H., Double Multiple Streamtube Model for Variable Pitch Vertical Axis Wind Turbines (American Institute of Aeronautics and Astronautics, 2013).

Strickland, J. H., "Darrieus turbine: A performance prediction model using multiple streamtubes," Report No. SAND750431, 1975.

Templin, R. J., “Aerodynamic performance theory for the NRC vertical-axis wind turbine," Laboratory Technical Report LTR-LA-160 (National Research Council of Canada, 1974).

Wang, L. B., Zhang, L., and Zeng, N. D., "An optimization method for improving hydrodynamics performance of the vertical axis turbine for tidal stream energy conversion,” J. Harbin Eng. Univ. 25(4), 417-422 (2004).

Xisto, C. M., Páscoa, J. C., Leger, J. A., and Trancossi, M., "Wind energy production using an optimized variable pitch vertical axis rotor," in Proceedings of Mechanical Engineers (The American Society of Mechanical Engineers, Montreal, Canada, 2014).

Zhang, L. X., Liang, Y. B., Wei, Y. X. et al., “Active variable pitch control laws for vertical axis wind turbine,” J. Cent. South Univ. 44(6), 2562-2568 (2013).

Zhang, L., Luo, Q. J., and Han, R. G., "Optimization of blade deflection angle of vertical-axis tidal current turbine," J. Harbin Inst. Technol. 2011(S1), 281-285.

Zhao, Z. Z., Yan, C., Wang, T. G., Xu, B. F., and Zheng, Y., "Study on approach of performance improvement of VAWT employing double multiple stream tubes model,” J. Sustainable Renewable Energy 9, 023305 (2017). 